\title{
Oxygen isotope fractionation in the vacuum ultraviolet photodissociation of carbon monoxide: Wavelength, pressure and temperature dependency.
}

\author{
Subrata Chakraborty ${ }^{1 *}$, Ryan Davis $^{1}$, Musahid Ahmed ${ }^{2}$, Teresa L. Jackson ${ }^{1}$, and \\ Mark H. Thiemens ${ }^{1}$ \\ ${ }^{1}$ Department of Chemistry and Biochemistry, University of California, San Diego, La Jolla, \\ California 92093-0356, ${ }^{2}$ Chemical Sciences Division, Lawrence Berkeley National Laboratory, \\ 1 Cyclotron Road, Berkeley, CA 94720 ( Communicating author: subrata@ucsd.edu)
}

\begin{abstract}
Several absorption bands exist in the VUV region of Carbon monoxide (CO). Emission spectra indicate that these bands are all predissociative. An experimental investigation of CO photodissociation by vacuum ultraviolet photons (90 to $108 \mathrm{~nm}$; 13 to $11 \mathrm{eV}$ ) from the Advanced Light Source Synchrotron and direct measurement of the associated oxygen isotopic composition of the products are presented here. A wavelength dependency of the oxygen isotopic composition in the photodissociation product was observed. Slope values $\left(\delta^{18} \mathrm{O} / \delta^{\prime 17} \mathrm{O}\right)$ ranging from 0.76 to 1.32 were observed in oxygen three-isotope space $\left(\delta^{18} \mathrm{O}\right.$ vs. $\left.\delta^{17} \mathrm{O}\right)$ which correlated with increasing synchrotron photon energy, and indicate a dependency of the upper electronic state specific dissociation dynamics (e.g., perturbation and coupling associated with a particular state). An unprecedented magnitude in isotope separation was observed for photodissociation at the 105 and $107 \mathrm{~nm}$ synchrotron bands and are found to be associated with accidental predissociation of the vibrational states ( $v=0$ and 1 ) of the upper electronic state $E^{1} \Pi$. For each synchrotron band, a large (few hundred per mil) extent of isotopic fractionation was observed and the range of fractionation is a combination of column density and exposure time. A significant temperature dependency in oxygen isotopic fractionation was observed, indicating a rotational level dependency in the predissociation process.
\end{abstract}




\section{Introduction}

Carbon monoxide (CO) is the second most abundant molecule in the universe after hydrogen. As a polar molecule $\mathrm{CO}$ radiates in the microwave region and emits in the radio wave region (2.6 and $1.3 \mathrm{~mm}$ lines) due to collisional deactivation with hydrogen in the interstellar medium ${ }^{1}$. These factors render $\mathrm{CO}$ an important molecule in radio astronomy and astrophysical research. A significant number of spectroscopic studies have been carried out in the last century to characterize the molecular parameters of CO to better interpret astronomical observations ${ }^{2-15}$. Recently, the oxygen isotopic yields associated with CO photochemistry in the early solar system were evaluated to interpret meteoritic isotopic compositions through isotope selfshielding of CO in the solar nebula ${ }^{16,17}$ and parent molecular cloud ${ }^{18,19}$, first suggested by Thiemens and Heidenreich ${ }^{20}$. Meteoritic oxygen isotope distributions are anomalous and do not depend upon relative masses. Theoretical models ${ }^{17,19}$ suffer from the lack of spectroscopic parameters of the rare isotopologue ${ }^{12} \mathrm{C}^{17} \mathrm{O}$ (for all $\mathrm{CO}$ absorption bands), and assumed equivalent to that of ${ }^{12} \mathrm{C}^{18} \mathrm{O}$ to produce the observed meteoritic isotope pattern ${ }^{17,19}$. Spectroscopic studies reveal that the line width and lifetime of the electronic excited state depends on the specific isotope species ${ }^{4,12}$, which argues against the assumption of equivalence of ${ }^{12} \mathrm{C}^{18} \mathrm{O}$ and ${ }^{12} \mathrm{C}^{17} \mathrm{O}^{21-22}$. The spectroscopic data ${ }^{4,12}$ exhibit an isotope dependency in CO predissociation process at different VUV absorption bands manifested through isotopologue specific line width measurements, however, isotopic fractionation associated with the predissociation process at these VUV bands cannot be easily calculated using these spectroscopic data. Recently, the isotope effect and extent of isotopic fractionation in the product nitrogen atoms from VUV photodissociation at certain wavelengths have been calculated ${ }^{23}$, though no such theoretical calculation exists for CO. In this paper we present experimentally measured isotopic 
fractionations associated with photodissociation of $\mathrm{CO}$ at various VUV wavelengths in the 90 to $108 \mathrm{~nm}$ spectral range using VUV photons from the Advanced Light Source (ALS) synchrotron at LBNL.

\section{Photochemical Processes and Isotopic Fractionation}

Molecular Photodissociation occurs via two processes: direct and indirect. In direct photodissociation, photoexcitation occurs from the electronic ground state (typically with $v=0$ ) directly to a repulsive state or to an energy region above the dissociation asymptote of a bound state. The Born-Oppenheimer Approximation (BOA) is utilized, assuming the electronic and nuclear motion in molecules can be separated and a molecular wave function can be expressed in terms of electron (r) and nuclear positions (R):

$$
\Psi_{\text {molecule }}(\mathrm{r}, \mathrm{R})=\psi_{\text {electrons }}(\mathrm{r}, \mathrm{R}) \psi_{\text {nuclei }}(\mathrm{R})
$$

The electronic wave function depends upon the nuclear positions (R) but not their velocities. The Condon Reflection Principle ${ }^{24}$ determines the R-dependence of an initial bound state reflected (via the repulsive surface, see Figure 1a) to the energy axis to evaluate the E-dependence of the cross-section, $\sigma(\mathrm{E})$. Consequently, the E-dependence of the $\sigma(\mathrm{E})$ values track the R-dependence of the initial bound state. In practice, $\sigma(E)$ is determined by composing a vertical line of length $E$ from the energy of the initial vibrational level ${ }^{25}$ (Figure 1 a). This vertical line is shifted left or right in $\mathrm{R}$ until it terminates on the repulsive potential energy curve. From this intersection point, the vertical line is reflected by $90^{\circ}$ and extended towards the energy axis. The maximum value of $\sigma(E)$ for a transition originating from the $v "=0$ level occurs at the energy of a vertical transition at a particular position (e.g., $\mathrm{R}_{\mathrm{e}}$ ). The width of $\sigma(\mathrm{E})$ is determined by the slope of the ground state potential energy curve at $\mathrm{R}=\mathrm{Re}$. When the potential energy curve is strongly repulsive, the shape of $\sigma(E)$ is strictly Gaussian. However, when the slope of the repulsive curve 
approaches zero, $\sigma(\mathrm{E})$ becomes distorted from a Gaussian shape. As the energy levels of the heavier isotopologues lie below in the ground state potential energy surface, it possesses a sharper non-Gaussian peak shape for $\sigma(E)$ (Figure 1a). The energy dependent isotopic fractionation factor in direct photodissociation may be expressed as:

$$
\varepsilon(\%)=\left[\left(\sigma_{\mathrm{H}}(\mathrm{E}) / \sigma_{\mathrm{L}}(\mathrm{E})\right)-1\right] \times 1000
$$

where $\sigma_{\mathrm{H}}(\mathrm{E})$ and $/ \sigma_{\mathrm{L}}(\mathrm{E})$ are the dissociation cross-sections of the heavy and light isotopologues, respectively.

Indirect photodissociation processes are more complex, since photo-excitation to a nominally bound vibrational-rotational level of an electronically excited state is predissociated by perturbative interaction with the continuum of another electronic state ${ }^{26}$ (Figure 1b). Direct predissociation occurs through various interaction modes, e.g., spin-orbit, hyperfine, electrostatic, rotational and, gyroscopic. The cross-section is governed by Fermi's Golden Rule, and depends on the coupling between the bound excited and dissociative states. The observation that the lighter isotopically substituted molecules preferentially dissociate, occurs for rotational and gyroscopic interactions where the ratio of the line-widths (the measure of interaction) for two isotopic species is proportional to the square of the ratio of their rotational constants or inversely proportional to the square of their reduced-mass $\left(1 / \mu^{2}\right)$ ratio. In this instance the lighter molecule dissociates at a greater rate than for the heavier species ${ }^{26}$. Phase differences between bound and continuum vibrational wave functions influence the line-width for dissociation based on the location of the crossing points of the two relevant electronic surfaces. The relative dissociation probability of different isotopically substituted species is subject to change associated with molecule specific transition probabilities to upper states. However, the relative line-widths change depends on the reduced mass of the molecular system. 
Predissociation may also proceed via an indirect process where the predissociated rotationalvibrational level is perturbed by another rotational-vibrational level that is directly predissociated by a third (unbound) state (Figure 1c). The accidentally predissociated level, having acquired an admixture of the perturber's wavefunction, borrows part of the characteristics of the perturbed state, in particular the line width. Indirect predissociation is also termed accidental predissociation. In accidental predissociation, the line broadening depends on the magnitude of the coupling matrix elements and accidental near degeneracies. The observed line widths are highly sensitive to isotopic substitution ${ }^{26-28}$. The BOA breaks down in this instance where the electronic wavefunction varies rapidly with $\mathrm{R}$. For indirect predissociation, a generalized formulation to calculate the isotopic fractionation, similar to that of direct photodissociation as shown through equation 2, is not possible to construct, but rather must be calculated for individual molecules. Recently, the isotopic fractionation during $\mathrm{N}_{2}$ photodissociation has been computed $^{23}$ through an ab-initio procedure, however, no such computation exists for CO. In the present experiments it will be shown the isotopic fractionation associated with each predissociation pathway are specific and depend on the dissociation dynamics of the relevant excited electronic states.

\section{Photoabsorption and dissociation bands of CO}

CO absorbs VUV photons at wavelength discrete lines and the excited Rydberg states are predominantly predissociated via interaction with continuum states ${ }^{2,3}$. A schematic of an energy level diagram compiled from different published values ${ }^{6,10,29-32}$ is shown in Figure 2. The relevant excited state predissociation occurs via rotational or electronic predissociation ${ }^{33}$. In the case of single electronic state involvement, its potential becomes quasi-repulsive at high values of $J$ because of a centrifugal contribution. For electronic predissociation, bound states partly mix 
with another electronic state that is repulsive. Laser-spectrometric analysis of $\mathrm{CO}^{4}$ have not found evidence of rotational predissociation mechanisms in the electronic states of CO.

There are approximately 41 strong absorption bands identified ${ }^{2-3,34}$ in the wavelength region 90 to $108 \mathrm{~nm}$. All absorption bands are not equally effective for CO dissociation. The absorption bands possessing the largest oscillator strength determine the predominant contribution to the photodissociation rate ${ }^{2-3}$.

\section{Experimental}

A windowless flow chamber with three stages of differential pumping (with a slight modification to that described in Chakraborty et $\mathrm{al}^{21}$ and shown in Figure 3) was used at the chemical dynamic beamline (9.0.2) of the Lawrence Berkeley National Laboratory synchrotron Advanced Light Source (ALS). Ultra high purity carbon monoxide (99.999\%) was passed through a cylindrical reaction chamber with lengths of 40,105, 1030 and $182.5 \mathrm{~cm}$ in four different experimental configurations at different constant pressures ranging from 39 to 490 mtorr. The combination of these two (chamber length and pressure) provide a range from $1.3 \mathrm{x}$ $10^{17}$ to $1.1 \times 10^{18}$ molecule/ $\mathrm{cm}^{2}$ in optical depth (cl) within the reaction chamber, which

effectively providing a differential optical shielding depth. VUV synchrotron photons $\left(5 \times 10^{14}\right.$ photons/sec) from the beamline (with an Ar gas filter to cut-off the higher harmonics) was aligned through three $\sim 3-\mathrm{mm}$ apertures of the three differential pumping sectors (with turbo molecular pumps with pumping capacity of 70, 1000 and 2000 liter/sec, respectively from the ALS beam entry port to the reaction chamber) and passed through the reaction chamber. The CO flow direction along the length of the reaction chamber is shown in the Figure 3, where CO photodissociation occur coaxially with the line of CO flow. 
A steady state flow (with a fixed pressure, measured by a capacitance manometer) was established inside the chamber before VUV photons are admitted to the chamber (by a gate valve) by controlling the flow of $\mathrm{CO}$ with a Baratron mass-flow controller. In this configuration the CO column density for an experimental run was predefined prior to photolysis. A stainless steel U-trap cooled with $\mathrm{LN}_{2}$ was placed between the CO-tank and the chamber to clean the input $\mathrm{CO}$ (by trapping any condensable contaminants such as $\mathrm{H}_{2} \mathrm{O}$ and $\mathrm{CO}_{2}$ ). During the entire irradiation period (7 to 15 hours) of $\mathrm{CO}$ of a fixed column density, three stainless spirals at the outlet of the reaction chamber are frozen in $\mathrm{LN}_{2}$. During VUV exposure, CO photodissociation produces $\mathrm{C}$ and $\mathrm{O}$ atoms with the O-atom recombining with $\mathrm{CO}$ to form $\mathrm{CO}_{2}$. The product $\mathrm{CO}_{2}$ was immediately collected in these spirals (at the outlet of CO flow) avoiding secondary photolysis. At the end of the exposure, CO flow was terminated and the cryogenic spirals isolated from the chamber and outlet pump. The spirals are thawed and refrozen to separate cocondensed $\mathrm{CO}$ from $\mathrm{CO}_{2}$ cryogenically. The uncondensed gas was pumped away and pure $\mathrm{CO}_{2}$ was collected in a sample tube for transport. At UCSD, the product $\mathrm{CO}_{2}$ was reacted with $\mathrm{BrF}_{5}$ following our conventional protocol ${ }^{35}$. The liberated gas was purified via gas chromatography (GC) and measured in a dual inlet, multi collector IRMS (Finnigan MAT 253) to determine the isotope ratios. Standard $\mathrm{CO}_{2}$ samples of known isotopic composition and of the same size as the actual samples were multiply measured as controls.

In the present experiments wide band (FWHM=0.25 eV) synchrotron photons (e.g., synchrotron band) were used. The spread of each synchrotron band is about $2.2 \mathrm{~nm}$ around the chosen central wavelength. The photon wavelength of interest was selected by varying the undulator gap of the beamline ${ }^{36}$. Six different synchrotron bands was used centered at 107.61, 105.17, $97.03,94.12,92.6,91.37 \mathrm{~nm}$, respectively to span the dissociation regime of 90 to 108 
$\mathrm{nm}$ and each synchrotron band was $2.2 \mathrm{~nm}$ (= FWHM) wide to maximize the photon flux to enhance the product $\mathrm{CO}_{2}$ amount for subsequent treatment. Due to wide nature of the synchrotron bands, several of the $\mathrm{CO}$ absorption bands lies within the envelop of each synchrotron band as shown in Figure 4. The significant CO absorption bands within each synchrotron band ${ }^{4,9-15,37}$ are described below:

A. CO band system within 105.5 to $109 \mathrm{~nm}$ (synchrotron band centered at $107.61 \mathrm{~nm}$ ) at wavelengths employed for the experiments

(i) $\mathrm{E}^{1} \Pi, v=1$ state of ${ }^{12} \mathrm{C}^{16} \mathrm{O}$ at $105.17, J=9,10,12$ are perturbed by the bound Rydberg state, $\mathrm{k}^{3} \Pi$ and dissociated through another repulsive state (strong indirect predissociation). Different set of $J$ values are perturbed for other CO isotopologues.

(ii) $\mathrm{C}^{1} \Sigma^{+}, v=1$ state of ${ }^{12} \mathrm{C}^{16} \mathrm{O}$ at 106.31 ; predissociation rates are rotational state independent ${ }^{12}$

(iii) $\mathrm{E}^{1} \Pi, v=0$ state of ${ }^{12} \mathrm{C}^{16} \mathrm{O}$ at $107.61, J=31$ is perturbed by the bound Rydberg state $\mathrm{k}^{3} \Pi$ and dissociated through another repulsive state (strong accidental predissociation), predissociation rates are isotopologue specific.

(iv) $\mathrm{C}^{1} \Sigma^{+}, v=0$ state of ${ }^{12} \mathrm{C}^{16} \mathrm{O}$ at 108.79 ; predissociation rates are rotational state independent B. CO band system within 103.5 to $106.5 \mathrm{~nm}$ (synchrotron band centered at $105.17 \mathrm{~nm}$ )

(i) $\mathrm{E}^{1} \Pi, v=1$ state of ${ }^{12} \mathrm{C}^{16} \mathrm{O}$ at $105.17, J=9,10,12$ are perturbed by the bound Rydberg state $\mathrm{k}^{3} \Pi$ and dissociated through another repulsive state (strong accidental predissociation).

(ii) $\mathrm{C}^{1} \Sigma^{+}$, v=1 state of ${ }^{12} \mathrm{C}^{16} \mathrm{O}$ at 106.31 ; predissociation rates are rotational state independent

(iii) $\mathrm{E}^{1} \Pi$, v=0 state of ${ }^{12} \mathrm{C}^{16} \mathrm{O}$ at 107.61 ; the $J=31$ is perturbed by the bound Rydberg state $\mathrm{k}^{3} \Pi$ and dissociated through another repulsive state (strong accidental predissociation), the predissociation rates are isotopologue specific.

C. CO band system: 95.5 to $99.0 \mathrm{~nm}^{38}$ (synchrotron band centered at $97.03 \mathrm{~nm}$ ) 
(i) $(4 \mathrm{p} \pi) \mathrm{L}^{1} \Pi$, $v=0$ state of ${ }^{12} \mathrm{C}^{16} \mathrm{O}$ at $96.83 \mathrm{~nm}$; with predissociation rates $\sim 3 \times 10^{10} \mathrm{~s}^{-1}$ and are rotational state dependent, the missing $Q(7)$ line is due to an accidental predissociation.

(ii) $(3 \mathrm{~d} \pi) \mathrm{L}{ }^{, 1} \Pi, v=1$ state of ${ }^{12} \mathrm{C}^{16} \mathrm{O}$ at $96.89 \mathrm{~nm}$; week spectra due to the fast predissociation rate $\sim 2.7 \times 10^{11} \mathrm{~s}^{-1}$ and are parity and rotational state independent.

(iii) $(4 \mathrm{p} \sigma) \mathrm{K}^{1} \Sigma$, v=0 state of ${ }^{12} \mathrm{C}^{16} \mathrm{O}$ at $97.03 \mathrm{~nm}$; with predissociation rate $\sim 2.2 \times 10^{10} \mathrm{~s}^{-1}$ and are rotational state independent (predissociation rate is constant up to $J=20$ ).

(iv) $(3 \mathrm{~s} \sigma) \mathrm{W}^{1} \Pi, v=0$ state of ${ }^{12} \mathrm{C}^{16} \mathrm{O}$ at $97.27 \mathrm{~nm}$; with predissociation rate $\sim 9.6 \times 10^{9} \mathrm{~s}^{-1}$ and are parity and rotational state dependent.

(v) ${ }^{1} \Sigma^{+}, v=0$ state of ${ }^{12} \mathrm{C}^{16} \mathrm{O}$ at $98.56 \mathrm{~nm}$

D. CO band system: 93.1 to $95.1 \mathrm{~nm}^{4}$ (synchrotron band centered at $94.12 \mathrm{~nm}$ )

(i) $(5 \mathrm{p} \pi)^{1} \Pi, v=0$ state of ${ }^{12} \mathrm{C}^{16} \mathrm{O}$ at $93.18 \mathrm{~nm}^{39}$; with predissociation rate $\sim 10^{11} \mathrm{~s}^{-1}$.

(ii) $(5 \mathrm{p} \sigma){ }^{1} \Sigma^{+}, v=0$ state of ${ }^{12} \mathrm{C}^{16} \mathrm{O}$ at $93.31 \mathrm{~nm}^{39}$; with predissociation rate $\sim 10^{10} \mathrm{~s}^{-1}$.

(iii) $(5 \mathrm{~s} \sigma) \mathrm{I}^{1} \Sigma^{+}, v=0$ state of ${ }^{12} \mathrm{C}^{16} \mathrm{O}$ at $94.02 \mathrm{~nm}$.

(iv) (3s $\sigma) \mathrm{W}^{1} \Pi, v=2$ state of ${ }^{12} \mathrm{C}^{16} \mathrm{O}$ at $94.12 \mathrm{~nm}$; with isotope dependent predissociation rates.

(v) $(4 \mathrm{~d} \sigma)^{1} \Sigma^{+}, v=0$ state of ${ }^{12} \mathrm{C}^{16} \mathrm{O}$ at $94.63 \mathrm{~nm}$; with an accidental predissociation at $J=22$ was evident and $J=8$ and 12 levels have highest predissociation rates of $1.2 \times 10^{11} \mathrm{~s}^{-1}$.

(vi) $(4 \mathrm{p} \sigma) \mathrm{H}^{1} \Sigma^{+}, v=1$ state of ${ }^{12} \mathrm{C}^{16} \mathrm{O}$ at $94.99 \mathrm{~nm}$

E. CO band system: 90.4 to $93.6 \mathrm{~nm}$ (two adjacent synchrotron bands centered at 91.4 and 92.6 $n m$ are merged for the sake of data analysis):

(i) ${ }^{1} \Pi, v=0$ state of ${ }^{12} \mathrm{C}^{16} \mathrm{O}$ at $91.27 \mathrm{~nm}$ (a weak spectra); predissociation rate $<3 \times 10^{10} \mathrm{~s}^{-1}$.

(ii) $(5 \mathrm{p} \sigma)^{1} \Sigma^{+}, v=1$ state of ${ }^{12} \mathrm{C}^{16} \mathrm{O}$ at $91.34 \mathrm{~nm}$ with predissociation rate $\sim 10^{11} \mathrm{~s}^{-1}$.

(iii) $(6 \mathrm{p} \sigma)^{1} \Sigma^{+}$, $v=0$ state of ${ }^{12} \mathrm{C}^{16} \mathrm{O}$ at $91.6 \mathrm{~nm}$, predissociation rate $<3 \times 10^{10} \mathrm{~s}^{-1}$. 
(iii) ${ }^{1} \Pi, v=2$ state of ${ }^{12} \mathrm{C}^{16} \mathrm{O}$ at $92.86 \mathrm{~nm}$ (a predissociation resonance is found at $J=8-9$ for ${ }^{12} \mathrm{C}^{16} \mathrm{O}$, a clear indication of an accidental predissociation).

(iv) $(5 \mathrm{p} \pi)^{1} \Pi, v=0$ state of ${ }^{12} \mathrm{C}^{16} \mathrm{O}$ at $93.18 \mathrm{~nm}^{4,39}$; with predissociation rate $\sim 3 \times 10^{11} \mathrm{~s}^{-1}$.

(v) $(5 \mathrm{p} \sigma)^{1} \Sigma^{+}, v=0$ state of ${ }^{12} \mathrm{C}^{16} \mathrm{O}$ at $93.31 \mathrm{~nm}^{39}$; with predissociation rate $\sim 10^{10} \mathrm{~s}^{-1}$.

For each these synchrotron bands, two sets of experiments were carried out at room temperature $\left(20^{\circ} \mathrm{C}\right.$ : $\left.\mathrm{RT}\right)$ and dry-ice temperature $\left(-78^{\circ} \mathrm{C}\right.$ : $\left.\mathrm{DI}\right)$, respectively to study the temperature dependency of the isotope effect.

\section{Results}

The results of the experiments are given in Table 1 . These experiments provide an extensive wavelength dependent data set of oxygen isotopic fractionation for CO photodissociation. Wavelength, pressure, and temperature dependency in the photodissociation process was experimentally investigated. Experimental conditions, results, sample amounts and isotopic composition of measured product $\mathrm{CO}_{2}$ and blank corrected values of atomic oxygen (CO photodissociation product) for each run are presented in Table 1. Raw data are corrected for fluorination blanks, determined from carefully measured amounts of tank $\mathrm{CO}_{2}$ fluorination of known oxygen isotopic composition. The isotopic composition of initial $\mathrm{CO}\left(\delta^{17} \mathrm{O}=25.5\right.$ and $\delta^{18} \mathrm{O}=51 \%$ ) was determined several times by conversion to $\mathrm{CO}_{2}$ through electric discharge (disproportionation) of CO (complete conversion), followed by fluorination and was used to calculate the atomic oxygen composition from the measured $\mathrm{CO}_{2}$-oxygen isotope value by isotopic mass balance. As shown in Table 1, the isotopic composition of product $\mathrm{CO}_{2}$ is heavily enriched compared to initial $\mathrm{CO}$ and is mass independent $\left(\delta^{17} \mathrm{O} \neq 0.5 \times \delta^{18} \mathrm{O}\right)$. The extent of isotopic enrichment is of the order of a few hundreds to a few thousands of per mil, depending 
upon experimental conditions (wavelength, column density, temperature, and exposure time). The oxygen isotopic composition of $\mathrm{CO}_{2}$ is shown in a conventional oxygen three-isotope plot (Figure 5 (a, b, c, d)) in a logarithmic scale (to incorporate the nonlinearity in cross $\delta$-plot for large $\delta$-values ${ }^{40}$ ). The product $\mathrm{CO}_{2}$ is enriched in all cases compared to initial $\mathrm{CO}$ composition, and the resultant isotopic composition is wavelength dependent. The range of isotopic composition at a particular wavelength derives from variation of column densities and exposure times. The room temperature $\left(20{ }^{\circ} \mathrm{C}\right.$ : RT) photolysis products at 107.61 and $105.17 \mathrm{~nm}$ are extended over a linear line with a slope value of $1.32 \pm 0.02$ (with an intercept of $-41.8 \pm 21 \%$ ), whereas the lower temperature $\left(-78{ }^{\circ} \mathrm{C}\right.$ : DI) products at $105.17 \mathrm{~nm}$ are fractionated more than for RT and define a lower slope of $1.21 \pm 0.01$ (with an intercept of $-124 \pm 25 \%$ ). The same temperature effect is seen for the $97 \mathrm{~nm}$ synchrotron band where the slope and intercept values for RT and DI temperatures are (1.07 \pm 0.06 and $-48 \pm 80 \%$ ) and (0.81 $\pm 0.09,98 \pm 67 \%$ ), respectively. The slope and the intercept values for the synchrotron bands at 94 and 91-92 nm for RT experiments are $(0.76 \pm 0.04,-31 \pm 34 \%$ ) and $(0.72 \pm 0.16,13.8 \pm 169 \%)$, respectively, and that for the DI temperature are $(0.77 \pm 0.12,-25 \pm 114 \%)$ and $(0.76 \pm 0.04,-11.8 \pm 39 \%)$, respectively. No temperature dependent trends in slope values are observed for these two synchrotron bands. The non-zero intercepts measured for all the trend lines (Figure 5 (a, b, c, d)) require involvement of more than one fractionating process, and of differing slope value. After photodissociation of $\mathrm{CO}$, atom-molecule recombination $\left(\mathrm{O}+\mathrm{CO} \rightarrow \mathrm{CO}_{2}\right)$ reaction takes place and it is known that the $\mathrm{O}+\mathrm{CO}$ recombination reaction yields non-mass dependent oxygen isotope effect as it goes through an excited metastable complex $\left(\mathrm{CO}_{2}\right)^{*}$ (in the order of 80 to 90 \%o in $\delta^{18} \mathrm{O}$ with a $\delta^{17} \mathrm{O} / \delta^{18} \mathrm{O}$ ratio of about 0.8$)^{41-42}$. However, the uncertainty associated with the measured intercept values (as mentioned above) are high because of the unprecedentedly high $\delta$ - 
values measured in the present experiment and therefore, it is difficult to distinguish the large primary isotope effect from photodissociation from the smaller secondary isotope effect from the recombination reaction and is neglected while calculating the isotopic composition of atomic oxygen composition from the measured isotopic composition of $\mathrm{CO}_{2}$ as shown in Table 1 . Incorporation of the recombination does not significantly alter the results.

Table 1 also shows the residence time ( $\tau=$ volume of the chamber/ flow rate) of $\mathrm{CO}$ in the reaction chamber and was obtained through precise measurement of volume of the chamber for each experimental configuration and the CO flow rate for each specific experimental run (by a 1sccm full scale MKS flow-meter). No relationship with the residence time was observed, either in isotopic composition or product $\mathrm{CO}_{2}$ yield, demonstrating that the measured amount and isotopic composition is not governed by the experimental parameters (i.e., pumping speed or flow rate) and is controlled by the isotopologue specific predissociation rates at different synchrotron bands as will be discussed. The $\mathrm{CO}_{2}$ yield is greater at lower wavelength (i.e., 97.03 and $94.12 \mathrm{~nm}$ ) bands compared to higher wavelength ones (i.e., 107.61 and $105.17 \mathrm{~nm}$ ).

\section{Discussion}

\section{Photochemical processes within the experimental beam-width}

When light passes through a column of gas which dissociates by line absorption, differential absorption of light occurs for the isotopologues and is proportional to their concentrations. As a result, when the spectral line corresponding to the major species saturates, the lines corresponding to the minor species do not and selective photodissociation of minor species occurs within the gas column, provided the band heads of the isotopologues are separated in 
energy space. This process is termed isotopic self-shielding (or isotope selective photodissociation) and is expressed through photon absorption:

$\frac{I}{I_{O}}=e^{-\sigma c l}$

where: $\mathrm{I}=$ photon flux at length $\mathrm{l}, \mathrm{I}_{\mathrm{o}}=$ initial photon flux at $\mathrm{l}=0, \mathrm{c}=$ concentration (molecules $\left.\mathrm{cm}^{-3}\right), \mathrm{l}=$ optical path length $(\mathrm{cm}), \sigma=$ cross section $\left(\mathrm{cm}^{2}\right)$. Considering the cross-sections for the isotopically substituted species to be the same, thus for a given photon flux and path length, the photon absorption scales with the abundance of the species.

Several absorption bands of CO satisfy the conditions for isotope selective photodissociation from optical shielding. According to this hypothesis, when the spectral line corresponding to the major species ${ }^{12} \mathrm{C}^{16} \mathrm{O}$ saturates, the lines corresponding to the minor species (e,g., ${ }^{12} \mathrm{C}^{17} \mathrm{O}$, ${ }^{12} \mathrm{C}^{18} \mathrm{O}$ ) do not, and the consequence is preferential production of ${ }^{17} \mathrm{O}$ and ${ }^{18} \mathrm{O}$ atomic oxygen species in the optical region of relevance ${ }^{3,34,43}$. This model assumes that there is no other isotope effect associated with photolysis (e.g., each photon absorption after light-shielding produces an immediate dissociation with no other isotopic fractionation process), and the oscillator strengths and predissociation probability for different isotopomers are identical to those for ${ }^{12} \mathrm{C}^{16} \mathrm{O}$ (e.g., no isotope selectivity). The measured isotopic compositions indicate that all accessible excited electronic states do not dissociate in the same fashion, otherwise similar isotopic compositions would have been seen. The observations rather show that different excited electronic states accessible to VUV photons follow different dissociation dynamics based on associated potential energy surfaces and local perturbations. In the following section the role of excited electronic states, i.e., positions in energy space, their mutual interactions and diabatic crossings (perturbation) and dissociation dynamics in the dissociation process and their explicit molecular dependency are discussed. 


\section{Isotopic Fractionation: Band Specific Observations}

The observed isotopic compositions measured for $\mathrm{CO}$ dissociation at different wavelengths (Figure 5a-d) require different relative fractions of $\mathrm{C}^{17} \mathrm{O}$ and $\mathrm{C}^{18} \mathrm{O}$ dissociation at different wavelengths. In the following sections we discuss the isotopic fractionation and associated factors for different wavelengths (synchrotron bands) separately.

\section{(A) $107.61 \mathrm{~nm}$ synchrotron band}

The FWHM of the synchrotron beam is $2.2 \mathrm{~nm}$, therefore within the $107.61 \mathrm{~nm}$ synchrotron bands, $105.17(E-X(1,0)), 106.31,107.61(E-X(0,0)$ and $108.79(C-X(0,0)) \mathrm{nm} C O$ bands are present (Figure 4; of these absorption bands, $108.79 \mathrm{~nm}$ absorption is non dissociative). However, each of these CO bands do not receive equal photon intensities. As the synchrotron beam is centered at $107.61 \mathrm{~nm}$, the CO band at this position receives the peak photon intensity, the CO bands at 106.31 and $105.17 \mathrm{~nm}$ receive 71 and $45 \%$ of the peak intensity, respectively. The integrated dissociation cross-sections of these three CO bands are 33.1, 1.66, $2.36\left(\times 10^{-18}\right.$ $\left.\mathrm{cm}^{2}-\mathrm{nm}\right)^{2}$, respectively. Convolving these two parameters with equation 3 , the dissociation contribution from $107.61 \mathrm{~nm} \mathrm{CO}$ band is $72 \%$, and the 106.31 and $105.17 \mathrm{~nm}$ CO bands contribute 18 and $10 \%$, respectively.

Self-shielding is only possible for a particular CO absorption band when the band heads of the isotopologs are separate. The separations are 49.26 and $51.18 \mathrm{~cm}^{-1}$ between band heads of $\mathrm{C}^{16} \mathrm{O}$ and $\mathrm{C}^{18} \mathrm{O}$ isotopologues for the 105.17 and $106.31 \mathrm{~nm}$ bands ${ }^{39}$, respectively. Consequently, both bands at 105.17 and $106.31 \mathrm{~nm}$ may self-shield. The band heads of ${ }^{12} \mathrm{C}^{16} \mathrm{O},{ }^{13} \mathrm{C}^{16} \mathrm{O},{ }^{12} \mathrm{C}^{17} \mathrm{O}$, and ${ }^{12} \mathrm{C}^{18} \mathrm{O}$ isotopologs for $107.61 \mathrm{~nm}$ band are very closely spaced (within $1 \mathrm{~cm}^{-1}$ ) 14,22 and are irresolvable lines (of Gaussian shape) for ${ }^{13} \mathrm{C}^{16} \mathrm{O},{ }^{12} \mathrm{C}^{17} \mathrm{O}$, and ${ }^{12} \mathrm{C}^{18} \mathrm{O}$, which render the 107.61 $\mathrm{nm}$ band a shielding band for ${ }^{12} \mathrm{C}^{16} \mathrm{O}$. As seen in Figure 1 of ${ }^{19}$ strong mutual shielding among 
minor isotopologues (e.g., ${ }^{13} \mathrm{C}^{16} \mathrm{O},{ }^{12} \mathrm{C}^{17} \mathrm{O}$, and ${ }^{12} \mathrm{C}^{18} \mathrm{O}$ ) is possible due to partial overlapping of these bands, resulting in shielding each other partially.

(B) $105.17 \mathrm{~nm}$ synchrotron band

The measured synchrotron beam intensity profile in energy space centered at $105.17 \mathrm{~nm}$ along with the contributing $\mathrm{CO}$ bands are shown in Figure 4 (also see Figure 2 of Chakraborty et al $\left.{ }^{22}\right)$. Within this $105.17 \mathrm{~nm}$ synchrotron band, CO absorption bands at $105.17(E-X(1,0)$, 106.31, $107.61(E-X(0,0))$ and $108.79(C-X(0,0)) \mathrm{nm}$ are present. Among these bands, the $108.79 \mathrm{~nm}$ band does not lead to dissociation ${ }^{2}$. The $105.17 \mathrm{~nm}$ band of CO receives the peak photon intensity of the synchrotron beam, whereas the bands at 106.31 and $107.61 \mathrm{~nm}$ receive 75 and $45 \%$ of the peak photon intensity, respectively. Convoluting with the dissociation integrated cross-section for these CO bands of $2.361 .66,33.3\left(\times 10^{-18} \mathrm{~cm}^{2}-\mathrm{nm}\right)^{2}$ respectively, for 105.17, 106.31 and $107.61 \mathrm{~nm}$, the estimated contributions in dissociation by the bands contained within synchrotron band at $105.17 \mathrm{~nm}$ are 53, 24 and $23 \%$, respectively. Therefore, the two shielding bands (at 105.17 and $106.31 \mathrm{~nm}$ ) collectively contribute $77 \%$ of the total dissociation in the $105.17 \mathrm{~nm}$ synchrotron bandwidth.

$E$ - $X(0,0)$ and $E-X(1,0)$ transitions are unique as the upper electronic state $E^{1} \Pi$ (a bound Rydberg state) for these transitions are associated with indirect predissociation ${ }^{44}$. The lower rovibronic states of $E^{1} \Pi$ are perturbed due to the presence of another triplet state $k^{3} \Pi^{9}, v=1$ level of $E^{1} \Pi$ are perturbed by the $v=6$ level of $k^{3} \Pi^{37}$. For the $v=1, J=9$ level, it is perturbed for ${ }^{12} \mathrm{C}^{16} \mathrm{O}$ ( $J=10$ and 2 levels are perturbed by other isotopologues $)^{10,13}$, whereas for $v=0$, levels near $J=$ 31 are perturbed. Predissociation from the $E^{1} \Pi$ state occurs via this bound Rydberg $\mathrm{k}^{3} \Pi$ state assisted by a repulsive state $\left({ }^{3} \Pi\right)$ to a channel $\mathrm{C}\left({ }^{3} \mathrm{P}\right)+\mathrm{O}\left({ }^{3} \mathrm{P}\right)$ and is a near-resonance phenomenon. In the present experiments the $v=0$ and $v=1$ states of $E^{1} \Pi$ are populated by VUV 
photon absorption at the 107.61 and $105.17 \mathrm{~nm}$ synchrotron bands, respectively (Figure 2) and produce dissociation through the accidental-predissociation pathway via spin-orbit coupling between singlet $\left(E^{1} \Pi\right)$ and triplet $\left(k^{3} \Pi\right)$ states.

It has been demonstrated from dissociation contribution analysis of the synchrotron bands centered at 105.17 and $107.61 \mathrm{~nm}$ that the shielding capable bands $E-X(1,0)$ and $C-X(1,0)$ are dominant for the former and non-shielding $E-X(0,0)$ band is dominant for the later ${ }^{22}$. A striking feature of the experimental results is that photolysis within each of the two synchrotron bands yield the same slope values of 1.32 in an oxygen-three isotope plot (Figure 5a) for the product Oatom generated from CO photolysis. This is inconsistent with a self-shielding mechanism ${ }^{3}$ as that requires equal ${ }^{17} \mathrm{O},{ }^{18} \mathrm{O}$ enrichments to explain the meteoritic measurements as described earlier. In each of these synchrotron bands, the major dissociation contributors $E-X(1,0)$ and $E-X(0,0)$ accidentally predissociate via electronic state perturbations. It is consequently appropriate to interpret the measured slope values as a near resonance phenomenon. This is consistent with the finding that the isotopologue specific lifetimes of the $E^{1} \Pi, v=1$ state are distinctly different ${ }^{15}$ due to the perturbation of $E{ }^{1} \Pi$ state by the perturbing $k^{3} \Pi$ state. Recently, it was shown that the isotope effect in Rydberg-Rydberg transition in $\mathrm{N}_{2}$ is position (and hence energy) dependent and therefore, is highly isotopologue specific ${ }^{23}$ for UV excitation of $\mathrm{N}_{2}$. As $\mathrm{N}_{2}$ and CO are isoelectronic, a similar energy dependent isotopic fractionation is expected for a Rydberg-Rydberg transition during accidental predissociation for the $v=0$ and $v=1$ states, which is not totally consistent with the argument that similar slope values measured in the oxygen isotopes for the 105.17 and $107.61 \mathrm{~nm}$ synchrotron bands are due to the isotopologue specific near-resonance accidental predissociation processes ${ }^{21}$. 
Considering that the synchrotron bands in the present experiments are wide compared to the narrow pulsed light used for the calculations ${ }^{23}$, the integrated isotope effect for each band must be quantitatively accounted for to resolve this differences. The CO absorption band $C^{1} \Sigma^{+}(v=1$; at $106.31 \mathrm{~nm})$ contributes in both synchrotron bands, but in unequal proportions. The predissociation rates of the $C^{1} \Sigma^{+}, v=1$ state are rotational state independent but depend highly upon the isotopologue species, similar to that of the $E{ }^{1} \Pi, v=1$ state (at $105.17 \mathrm{~nm}$ ). However, the predissociation rates are higher for heavier isotopologues, opposite of the $E{ }^{1} \Pi, v=1$ state ${ }^{12}$ and contribution from the $C^{1} \Sigma^{+}$may contribute to the observations of equal slope values in the two synchrotron bands.

(C) $97.03 \mathrm{~nm}$ synchrotron band

Several CO absorption bands exist in the synchrotron band centered around the $97.03 \mathrm{~nm}$ synchrotron band and, encompass at least six CO bands (at $96.83(L-X(0,0), 96.89(L-X(1,0)$ ), $97.03(K-X(0,0)), 97.27(W-X(0,0))$ and, $98.56(J-X(0,0)) \mathrm{nm}$, Figure 4) have dissociation crosssection of $\sim 10^{-17}\left(\mathrm{~cm}^{2}-\mathrm{nm}\right)^{2}$. The photon peak intensities absorbed by these bands are 72,75 , 100, 84 and $50 \%$, respectively, or dissociation contributions of $19,20,35,16$ and $10 \%$, respectively. Among these five bands, $97.03(K-X(0,0))$ and $98.56(J-X(0,0)) \mathrm{nm}$ bands may not self-shield since the band heads of the different isotopologues are indistinguishable (wavel ength separation within $1 \mathrm{~cm}^{-1}$ ). Consequently, 50\% of total dissociation was via shielding bands and the residual $50 \%$ by non-shielding bands.

The measured slope value, or $\delta^{17} \mathrm{O} / \delta^{18} \mathrm{O}$ ratio, (in O-atom reservoir) in a oxygen three isotope plot is 1.07 (Figure $5 b$ ). The extent of heavy isotope enrichment $\left(\delta^{17} \mathrm{O}\right.$ and $\left.\delta^{18} \mathrm{O}\right)$ is similar to that observed for the 105.17 and $107.61 \mathrm{~nm}$ synchrotron bands. All CO bands associated with this synchrotron wavelength band predissociate. The $(4 \mathrm{p} \pi) L{ }^{1} \Pi, v=0$ state at $96.83 \mathrm{~nm}$ possesses an 
accidental predissociation character ${ }^{4,11}$. The e-parity components undergo coupling with the $\mathrm{D}^{1} \Sigma^{+}$repulsive state, giving rise to a $J$-dependent interaction and predissociation rate. Additionally, a $J$-dependent predissociation is found for e and f-parity states arising from the strong interaction between the $L{ }^{1} \Pi, v=0$ other ${ }^{1} \Pi$ states (notably $L^{\prime}{ }^{1} \Pi$ state) ${ }^{11}$. Local perturbations also occur associated with accidental predissociation and from line broadening at $J=7,10$, and 15 for ${ }^{12} \mathrm{C}^{16} \mathrm{O}$ and ${ }^{13} \mathrm{C}^{16} \mathrm{O}$ and is not observed for ${ }^{13} \mathrm{C}^{18} \mathrm{O}$.

The next band, $(3 \mathrm{~d} \pi) L^{, 1} \Pi, v=1$ state at $96.89 \mathrm{~nm}$ predissociates rapidly $\left(\sim 2.7 \times 10^{11} \mathrm{~s}^{-1}\right)$ and is known to be parity and rotational state independent. Similarly, a rotational state independent predissociation takes place for $(4 \mathrm{p} \sigma) K^{1} \Sigma, v=0$ state $^{4}$ at $97.03 \mathrm{~nm}$ with the upper electronic state $C^{1} \Sigma$ becoming populated and, coupled to another singlet-triplet cross-over, dissociates through the $\mathrm{C}\left({ }^{1} \mathrm{D}\right)+\mathrm{O}\left({ }^{3} \mathrm{P}\right)$ channel. The oscillator strengths in this band for the isotopologues ${ }^{12} \mathrm{C}^{16} \mathrm{O},{ }^{13} \mathrm{C}^{16} \mathrm{O}$, and ${ }^{13} \mathrm{C}^{18} \mathrm{O}$ are nearly identical ${ }^{45}$.

The three CO bands are most effective in dissociation for the $97.03 \mathrm{~nm}$ synchrotron band. The unavailability of lifetimes and oscillator strengths for the ${ }^{17} \mathrm{O}$ containing isotopologue of CO for any of these transitions limits the exact interpretation of the measured slope value (1.07, Figure 5b) in the synchrotron band. Predissociation rates of some CO bands show isotopologue specific values $^{38}$, suggesting preference of one isotopologue over the other in the dissociation pathway. This is a consequence of a perturbation governed resonance effect in coupling one quasi bound state to another leading to dissociation. The resonance effects are not mass governed and hence the observed mass-independent slope value may reflect the resonance effect.

Rotational and parity (e/f) resolved lifetimes of $L^{1} \Pi, W^{1} \Pi$ and $K^{1} \Sigma^{+}$excited states have been experimentally determined using a narrow band extreme-UV laser source ${ }^{46}$. For the $W^{1} \Pi$ state, a radiative lifetime of 4 nanosecond was derived ${ }^{47}$ through $a b$ initio calculations. Convoluting the 
experimentally determined natural lifetime of 130 ps with the radiative lifetime, Ubachs et al. ${ }^{46}$ concluded that the $\Pi_{\mathrm{f}}$ (f-parity) component of $W^{1} \Pi(v=0)$ state is predissociated by $96.6 \%$ and the $3.3 \%$ radiative decay will populate the vibrationally excited states of the electronic ground state. The experimentally determined 1.0 nanosecond lifetime of $(4 \mathrm{p} \pi) L{ }^{1} \Pi, v=0$ was suggested to be an effect of purely radiative decay ${ }^{46}$. These non-predissociative/ partial-predissociative states may generate an isotope effect upon the end product (e.g., predissociation product (Oatom) by the entire synchrotron band).

(D) $94.12 \mathrm{~nm}$ synchrotron band

CO absorptions bands within the envelope of this synchrotron band are at 93.31, 94.02, $94.12,94.63,94.99 \mathrm{~nm}$ with dissociation cross-sections of $30.9,16.7,20.2,6.04,17.6\left(10^{-18} \mathrm{~cm}^{2}-\right.$ $\mathrm{nm})^{2}$, respectively. The position of these bands corresponds to available photon flux intensities of $60,72,100,80$ and $70 \%$ respectively. Combination of the photon flux and the corresponding cross-sections yield the dissociation contributions for these CO bands as 27, 17, 30, 7 and, $18 \%$ respectively. Among these CO bands, only $94.12 \mathrm{~nm}$ band may self-shield as the peak heads of isotopol ogues are separated be more than $2 \mathrm{~cm}^{-1} 48$.

Included in this synchrotron wavelength band are two CO bands, the $(3 s \sigma) W^{1} \Pi, v=2$ state at $94.12 \mathrm{~nm}$ and the $(4 \mathrm{~d} \sigma)^{1} \Sigma^{+}, v=0$ state at $94.63 \mathrm{~nm}$. Mass-independent isotopic fractionations (slope, $\delta^{17} \mathrm{O} / \delta^{18} \mathrm{O}>0.5$ ) are observed (Table1 and Figure 5c). The measured slope value for this synchrotron band is 0.76 . The range of the heavy isotope enrichment $\left(\delta^{17} \mathrm{O}\right.$ and $\left.\delta^{18} \mathrm{O}\right)$ is significantly smaller than the other three measured synchrotron bands (Table 1). An accidental predissociation at $J=22$ was documented for the later state $\left((4 \mathrm{~d} \sigma)^{1} \Sigma^{+}, v=0\right)$. The mass independent isotopic character in the slope value may be due to the isotopologue specific predissociation rate of ${ }^{1} \Pi$ and ${ }^{1} \Sigma^{+}$states (as described in section IV). 


\section{(E) 91-92 $\mathrm{nm}$ synchrotron band}

Several CO absorption bands are present in this spectral region due to the close spacing of $\operatorname{states}^{48}$. The dissociation cross-section of all the bands identified by Eidelsberg et $\mathrm{al}^{2}$ and Eikema et $\mathrm{al}^{4}$ are not known and therefore, the dissociation contribution by different $\mathrm{CO}$ bands cannot be quantified for this pair of synchrotron bands.

With the exception of the ${ }^{1} \Pi, v=2$ state at $92.86 \mathrm{~nm}$, where a predissociation resonance is located at $J=8-9$ for ${ }^{12} \mathrm{C}^{16} \mathrm{O}$ clearly indicating accidental predissociation, all other bands proceed via normal predissociation ${ }^{4}$. The measured slope value in oxygen three isotope plot $\left(\delta^{17} \mathrm{O} / \delta^{18} \mathrm{O}\right)$ is 0.76 (Figure $5 \mathrm{~d}$ ). The extent of heavy isotope enrichment $\left(\delta^{17} \mathrm{O}\right.$ and $\left.\delta^{18} \mathrm{O}\right)$ is similar to that observed for the $94.12 \mathrm{~nm}$ synchrotron band, but smaller than that observed for the other three synchrotron bands (97.03, 105.17 and $107.61 \mathrm{~nm})$. The slight non-mass dependence in the slope value may be due to the isotopologue specific predissociation rate of ${ }^{1} \Pi$ state.

\section{Column Density Dependent Isotopic Fractionations}

A large isotope effect is expected due to isotope self-shielding during photon absorption process following equation 3 . As the equation shows, the fractionation scales with gas column density and absorption cross-section for a specific wavelength. In the present experiment a large fractionation was measured in ${ }^{18} \mathrm{O}$ and ${ }^{17} \mathrm{O}$ for each synchrotron band, and the measured fractionation increased with increasing column density (Table 1). However, when the measured fractionations among different synchrotron bands are compared for a particular temperature and column density, it was observed that the synchrotron band with largest total absorption cross section (adding up the integrated cross section for all the CO bands within the synchrotron band) does not depict the largest fractionation. This observation is inconsistent with the concept that 
the fractionation only depends on the differential isotopic photon absorption. The measured slope values (as shown in Figure 5a) are plotted against the column densities in Figure 6 for $105.17 \mathrm{~nm}$ synchrotron band (both for RT $\left(20^{\circ} \mathrm{C}\right)$ and DI $\left(-78{ }^{\circ} \mathrm{C}\right)$ experiments). The measured slope values remain essentially constant with a column density variation of nearly one order of magnitude (2.6 $\times 10^{17}$ to $1.2 \times 10^{18}$ molecules $/ \mathrm{cm}^{2}$ ). The experiment column densities are such that ${ }^{12} \mathrm{C}^{16} \mathrm{O}$ lines are opaque (i.e., the value of $I / I_{o}$ of eqn. 3 are $<0.5$ for all the experimental runs) and the lines for minor isotopologues transparent ${ }^{22}$ (i.e., the value of $I / I_{o}$ of eqn. 3 are $>0.92$ for all the experimental runs), and ideal for observing isotopic self-shielding. If isotope self-shielding were the only explanation for the observed mass independent isotopic fractionation, the slope values should have increased from lower to higher values in the given column density range instead of remaining nearly constant (Figure 6). This requires significant additional isotope effects in the predissociation process beyond the isotope effect due to differential light absorption (selfshielding). The observed slope values greater than 1.0 measured for the 105.17 and $107.61 \mathrm{~nm}$ synchrotron bands was previously interpreted as the effect of high column density and saturation of ${ }^{12} \mathrm{C}^{18} \mathrm{O}$ line along with the ${ }^{12} \mathrm{C}^{16} \mathrm{O}$ line ${ }^{49}$. An absorption calculation (following equation 3) yields slope values of 1.05 and 1.08 respectively, for two experimental runs ALS-07-07 and ALS-07-15, for the 105.17 and $107.61 \mathrm{~nm}$ synchrotron bands, respectively using integrated cross-sections of $0.3 \times 10^{-17}$ and $5 \times 10^{-17} \mathrm{~cm}^{-}-\mathrm{nm}^{50}$ for these two CO bands. Even when the cross section for the later was artificially increased by one order of magnitude, the slope value does not deviate from the previous value (when plotted in the three-isotope plot in ln-form as used in Fig 5a). This rules out a saturation effect of ${ }^{12} \mathrm{C}^{18} \mathrm{O}$ lines for the column densities employed in the experiments. 
The lower than one slope values for higher energy synchrotron experiments (94 through 91 nm synchrotron bands) may be explained by an additional mass-dependent fractionation along with the slope one fractionation due to self-shielding. The extent of fractionation due to differential photon absorption is a few hundreds of permil, thus a few tens of permil additional mass-dependent fractionation would not lower the measured slope values (Figure $5 c$ and $5 d$ ). In sum, the measured column density dependent isotopic fractionation cannot be explained by differential photon absorption and an additional mass-independent fractionation arising from predissociation processes, is required to explain the present measurements.

\section{Temperature Dependent Isotopic Fractionation}

A significant feature of the observed isotope effect is the dry ice temperature (DI: $-78{ }^{\circ} \mathrm{C}$ ) data. For 107.61, 105.17, and $97.03 \mathrm{~nm}$ (Figure 5a, 5b and 6), the slope values decrease significantly to 1.2 and 0.81 , respectively at DI, from 1.32 and 1.07 at RT. For the other two higher energy synchrotron bands at 94.12 and $91-92 \mathrm{~nm}$, the DI slope values remain the same as that for RT. Apart from the slope values, the measured $\delta^{17} \mathrm{O}$ and $\delta^{18} \mathrm{O}$ values (Table 1 ) at lower temperatures $-78{ }^{\circ} \mathrm{C}$ are larger compared to their $20{ }^{\circ} \mathrm{C}$ counterpart (i.e., except temperature, all other experimental parameters are the same).

The calculated collisional timescales for the two temperatures used in the present experiment for a particular pressure (Table 1) provide a narrow range in the order of microseconds. These time scales are significantly larger than the predissociation time scales, while are a few hundred picoseconds to 1.8 nanoseconds for the $E^{1} \Pi(v=0,1), C^{1} \Sigma^{+}(v=0,1), L^{1} \Pi(v=0), K^{1} \Sigma^{+}(v=0)$, and $W^{1} \Pi(v=0)$ states $^{12,15,37,46}$. Therefore, the measured isotopic fractionation with the change in temperature (or the column density as described in previous section) cannot be attributed to the collisional time scale difference. 
Most of the CO bands within 107.61, 105.17 and $97.03 \mathrm{~nm}$ synchrotron bands predissociate, depending upon the rotational states ( $J$-value dependent) values, whereas, the majority of the CO bands within 94.12 and 91-92 nm synchrotron bands show $J$-value independent predissociation ${ }^{4}$ (as described in section IV). It is known that with increasing temperature, the $\mathrm{P}$ and $\mathrm{R}$ branches of an electronic band shift away from each other and become flatter (i.e., reduction in peak height $)^{51}$. Spectroscopic observations show the $J$-dependency through line broadening effects for different CO isotopologues due to resonances in the $E^{1} \Pi(v=1)$ state at $105.17 \mathrm{~nm}^{37}$. Based on the above $J$-dependency of predissociation rates of CO isotopologues, it may be inferred that the temperature dependency of the isotopic fractionation arise from the $J$-dependent predissociation rates and the temperature dependency of rotational energy distribution ${ }^{51}$. The higher enrichment at lower temperature may be due to sharper band heads as described above. The slope value in the oxygen three-isotope plot depends on the predissociation rates of ${ }^{17} \mathrm{O}$ and ${ }^{18} \mathrm{O}$ for the isotopologues of CO. A simple photon absorption calculation (using Beers-Lambert law, i.e., equation 3) for the present experimental condition shows that an enhanced predissociation rate of $\mathrm{C}^{18} \mathrm{O}$ (compared to $\mathrm{C}^{17} \mathrm{O}$ ) by only $0.4 \%$ can reduce the slope value by 0.12 as measured (Figure 5a) for $105.17 \mathrm{~nm}$ synchrotron band. Given the fact that the spectroscopically determined predissociation rates ${ }^{37}$ are associated with an uncertainty of at least $10 \%$, the possibility of a small rate difference of less than a percent level is not unreasonable. The predissociations are perturbation governed and are not mass-dependent ${ }^{52}$, therefore, slight rate difference among isotopologues are also possible.

Collectively, the accessible upper electronic states via VUV photons are spectroscopically complex as a consequence of closely spaced absorption bands and the number of isoenergetic Rydberg and valance states. The presence of these states produces significant perturbations of the 
electronic states and introduces an additional factor in interpretation of the isotope specific dissociation pathways. As shown for $\mathrm{N}_{2}$ molecules, the major photodissociation isotope effects are after the transition to the upper electronic state through photon absorption, where the dissociation pathways follow through perturbed interaction surfaces ${ }^{23}$. Based upon the experimental results we cannot specifically identify the isotope effect associated with each of the spectroscopic entities (i.e., oscillator strengths, dissociation line widths, predissociation rates), however, the experiments have extended understanding of photodissociation process. Unlike $\mathrm{N}_{2}$, the excited energy surfaces are not as well characterized for CO, consequently exact calculation of wavelength dependent isotopic fractionations for $\mathrm{CO}$ photodissociation are yet possible. These experiments represent a first step towards detailed understanding of perturbation dominated isotopologue specific variations in photodissociation, a key for quantitative determination of $\delta^{17} \mathrm{O}, \delta{ }^{18} \mathrm{O}$ composition of $\mathrm{CO}$ dissociation products in the astrophysical environments and for other molecules.

\section{Summary}

CO isotopic photodissociation at five different VUV spectral regions (FWHM $\sim 2 \mathrm{~nm}$ ), extending from 90 to $108 \mathrm{~nm}$ was carried out. The oxygen isotopic composition of product $\mathrm{CO}_{2}$ was measured and the pressure and temperature dependency of the isotopic fractionation process studied. An unprecedented magnitude of isotopic fractionation in the product ${ }^{17} \mathrm{O}$ and ${ }^{18} \mathrm{O}$ was observed. The process primarily depends upon wavelength, with a specific $\delta^{17} \mathrm{O} / \delta^{18} \mathrm{O}$ value observed at different wavelength regions. Isotopologue specific predissociation rates are suggested as the dominant mechanism in accounting for the observed wavelength specific isotope values over and above the isotope effect due to differential photon absorption by 
different CO isotopologues. Spectroscopic parameters for all minor isotopologues are not available and therefore, the measured $\delta$-values are of value in modeling the oxygen isotopic fractionation during CO photodissociation as they reflect these values.

\section{Acknowledgements}

SC and MHT acknowledge funding support from NASA through Cosmochemistry and Origin programs. MA and the ALS are supported by the Director, Office of Energy Research, Office of Basic Energy Sciences, Chemical Sciences Division of the U.S. Department of Energy under contract No. DE-AC02-05CH11231. We gratefully acknowledge support from Sarah Ferrell and Drs. Amir Golan and Oleg Kostko of Chemical Dynamics Beamline of ALS in setting up the experiment and beam alignment. We also acknowledge Dr. Oleg Kostko for measuring the ALS beam profiles for different energy settings. SC and MHT acknowledge valuable discussion with Drs. G. Dominguez, R. Shaheen, and A Priyadarshi. SC and MHT acknowledge insights from Prof. R. D. Levine and B. H. Muskatel of Hebrew University, Jerusalem. 


\section{References}

W. Klemperer, Proceedings of the National Academy of Sciences 103 (33), 12232 (2006).

C. Letzelter, M. Eidelsberg, F. Rostas, J. Breton, and B. Thieblemont, Chemical Physics 114, 16 (1987).

E. F. vanDishoeck and J. H. Black, Astrophysical Journal 334 (Nov), 32 (1988).

K. S. E. Eikema, W. Hogervorst, and W. Ubachs, Chemical Physics 181 (1-2), 217 (1994).

J. Baker, Journal of Molecular Spectroscopy 234 (1), 75 (2005).

J. Baker and F. Launay, The Journal of Chemical Physics 123 (23), 234302 (2005).

J. Baker and F. Launay, Chemical Physics Letters 404 (1-3), 49 (2005).

J. Baker and F. Launay, Journal of Molecular Spectroscopy 203 (1), 196 (2000).

J. Baker and F. Launay, Journal of Molecular Spectroscopy 165 (1), 75 (1994).

J. Baker, J. L. Lemaire, S. Couris, A. Vient, D. Malmasson, and F. Rostas, Chemical Physics 178 (1-3), 569 (1993).

P. Cacciani, F. Brandi, J. P. Sprengers, A. Johansson, A. L'Huillier, C. G. Wahlström, and W. Ubachs, Chemical Physics 282 (1), 63 (2002).

P. Cacciani, F. Brandi, I. Velchev, C. Lyngå, C. G. Wahlström, and W. Ubachs, The European Physical Journal D - Atomic, Molecular, Optical and Plasma Physics 15 (1), 47 (2001).

P. Cacciani, W. Hogervorst, and W. Ubachs, The Journal of Chemical Physics 102 (21), 8308 (1995).

P. Cacciani and W. Ubachs, Journal of Molecular Spectroscopy 225 (1), 62 (2004).

P. Cacciani, W. Ubachs, P. C. Hinnen, C. Lynga, A. L'Huillier, and C.-G. Wahlstrom, The Astrophysical Journal Letters (2), L223 (1998).

R. N. Clayton, Nature 415 (6874), 860 (2002).

J. R. Lyons and E. D. Young, Nature 435 (7040), 317 (2005).

H. Yurimoto and K. Kuramoto, Science 305 (5691), 1763 (2004).

R. Visser, E. van Dishoeck, F., and J. Black, H., A\&A 503 (2), 323 (2009).

J. E. Heidenreich and M. H. Thiemens, Journal of Chemical Physics 78 (2), 892 (1983).

S. Chakraborty, M. Ahmed, T. L. Jackson, and M. H. Thiemens, Science 321 (5894), 1328 (2008).

S. Chakraborty, M. Ahmed, T. L. Jackson, and M. H. Thiemens, Science 324 (5934), 4 (2009).

B. H. Muskatel, F. Remacle, M. H. Thiemens, and R. D. Levine, Proceedings of the National Academy of Sciences 108 (15), 6 (2011).

M. S. Child and M. Shapiro, Molecular Physics: An International Journal at the Interface Between Chemistry and Physics 48 (1), 111 (1983).

C. E. Miller and Y. L. Yung, J. Geophys. Res. 105.

H. Lefebvre-Brion and R. W. Field, The Spectra and Dynamics of Diatomic Molecules, 2nd ed. (Elsevier Academic Press, 2004).

H. Lefebvre-Brion and R. Colin, Journal of Molecular Spectroscopy 65 (1), 33 (1977).

A. J. Lorquet and J. C. Lorquet, Chemical Physics Letters 26 (1), 138 (1974).

D. L. Cooper and K. Kirby, The Journal of Chemical Physics 87 (1), 424 (1987).

K. Kirby and D. L. Cooper, The Journal of Chemical Physics 90 (9), 4895 (1989). 
A. Mellinger and C. R. Vidal, The Journal of Chemical Physics 101 (1), 104 (1994).

S. Wilson, International Journal of Quantum Chemistry 12 (4), 609 (1977).

G. Herzberg, Chemical Reviews 20 (1), 145 (1937).

S. Warin, J. J. Benayoun, and Y. P. Viala, Astronomy and Astrophysics 308 (Apr), 29 (1996).

S. K. Bhattacharya and M. H. Thiemens, Zeitschrift Fur Naturforschung Section a-a Journal of Physical Sciences 44 (9), 811 (1989).

P. A. Heimann, M. Koike, C. W. Hsu, D. Blank, X. M. Yang, A. G. Suits, Y. T. Lee, M. Evans, C. Y. Ng, C. Flaim, and H. A. Padmore, Review of Scientific Instruments 68 (5), 1945 (1997).

W. Ubachs, I. Velchev, and P. Cacciani, The Journal of Chemical Physics 113 (2), 547 (2000).

M. Drabbels, J. Heinze, J. J. ter Meulen, and W. L. Meerts, The Journal of Chemical Physics 99 (8), 5701 (1993).

M. Eidelsberg and F. Rostas, A\&A 235 (1-2) (1990).

M. F. Miller, Geochimica Et Cosmochimica Acta 66 (11), 1881 (2002).

S. K. Bhattacharya and M. H. Thiemens, Zeitschrift Fur Naturforschung Section a-a Journal of Physical Sciences 44 (5), 435 (1989).

A. Pandey and S. K. Bhattacharya, The Journal of Chemical Physics 124 (23), 234301 (2006).

Y. Sheffer and et al., The Astrophysical Journal Letters 572 (1), L95 (2002).

J. D. Simmons and S. G. Tilford, Journal of Molecular Spectroscopy 49 (1), 167 (1974).

M. Eidelsberg, J. L. Lemaire, J. H. Fillion, F. Rostas, S. R. Federman, and Y. Sheffer, A\&A 424 (1), 355 (2004).

W. Ubachs, K. S. E. Eikema, W. Hogervorst, and P. C. Cacciani, J. Opt. Soc. Am. B 14 (10), 2469 (1997).

D. L. Cooper and K. Kirby, Chemical Physics Letters 152 (4-5), 393 (1988).

M. Eidelsberg, J. J. Benayoun, Y. Viala, F. Rostas, P. L. Smith, K. Yoshino, G. Stark, and C. A. Shettle, Astronomy and Astrophysics 265 (2), 839 (1992).

J. R. Lyons, R. S. Lewis, and R. N. Clayton, Science 324 (5934) (2009).

G. Stark, P. L. Smith, K. Ito, and K. Yoshino, Astrophysical Journal, Part 1 (ISSN 0004637X) 395 (2), 5 (1992).

G. Herzberg, Molecular Spectra and Molecular Structure: Spectra of Diatomic Molecules 2nd ed. (Krieger Pub Co, 1989).

H. Lefebvre-Brion and B. R. Lewis, Molecular Physics 105 (11-12), 1625 (2007).

\section{Figure Captions}

Figure 1. Schematic diagram showing different kinds of photodissociation schemes. (a) direct dissociation, where transition is from the ground state to an upper repulsive surface leading to dissociation, (b) direct predissociation, where transition from the ground state populates a bound upper electronic state. Cross-over of a repulsive surface with this bound state facilitates dissociation, (c) indirect pre-dissociations is different from direct predissociation in the way that 
instead of bound-repulsive cross-over, two bound state crosses and the dissociation takes place via a repulsive surface crossing the second bound surface. Isotopic fractionation for direct dissociation can be estimated easily, however those for predissociation are complicated because of perturbations involved during curve crossing.

Figure 2. Schematic and partial potential energy level diagram of CO showing the positions of the every levels used in these experiments along with their corresponding upper electronic states. A major phenomenon of accidental predissociation is schematically shown where the Rydberg state $E{ }^{1} \Pi$ crosses over another Rydberg state $k^{3} \Pi$ and the later finally dissociates through a ${ }^{3} \Pi$ repulsive state. $E-X(1,0)$ and $(0,0)$ transitions are demonstrated to follow the accidental predissociation pathways and unusual oxygen isotopic fractionation was observed for these two synchrotron bands.

Figure 3. Schematic diagram of the experimental set-up used in Chemical Dynamics Beamline at the Advanced Light Source for CO photo dissociation experiment. Three stage differential pumping system was used with the reaction chamber of different lengths $(48,105,130$, and $182.5 \mathrm{~cm}$ ) for different experimental runs to generate significant variation in column densities (and residence time) when combined with pressures used.

Figure 4. The measured synchrotron beam profiles centered at six different energies within 90 through $110 \mathrm{~nm}$ wavelength regime used in this experiment (left Y-axis shows the beam current). The position of $\mathrm{CO}$ absorption bands are shown by vertical lines corresponding to their absorption cross section (right Y-axis).

Figure 5. Oxygen isotopic composition shown in three-isotope plot $\left(\delta^{18} \mathrm{O}\right.$ vs $\left.\delta^{17} \mathrm{O}\right)$ measured in different synchrotron bands at two different temperature settings $20{ }^{\circ} \mathrm{C}(\mathrm{RT})$ and $-78{ }^{\circ} \mathrm{C}$ (DI) in logarithmic scale (a) centered at 105.17 and $107.61 \mathrm{~nm}$, depicting a combined slope value of 1.32 for RT and 1.21 for $105.17 \mathrm{~nm}$ at DI temperature, (b) centered at $97.03 \mathrm{~nm}$ showing a slope values of 1.07 and 0.81 for RT and DI temperatures, respectively, (c) centered at $94.12 \mathrm{~nm}$ showing a slope value of 0.76 both for RT and DI temperatures, (c) centered at 91-92 nm showing a slope value of 0.76 both for RT and DI temperatures. 
Figure 6. Measured slope values obtained from $105.1720{ }^{\circ} \mathrm{C}$ (RT) and $-78{ }^{\circ} \mathrm{C}$ (DI) nm synchrotron band experiments are plotted against column densities. The slope values are nearly constant in the varied column density regime, which does not support self-shielding as described in the text.

\section{Table Caption}

Table 1. Compilation of all experimental parameters and conditions used in CO photodissociation experiments along with measured oxygen isotopic compositions (linear and logarithmic form). The calculated oxygen isotopic composition of atomic oxygen (CO dissociation product) are tabulated in last three columns.

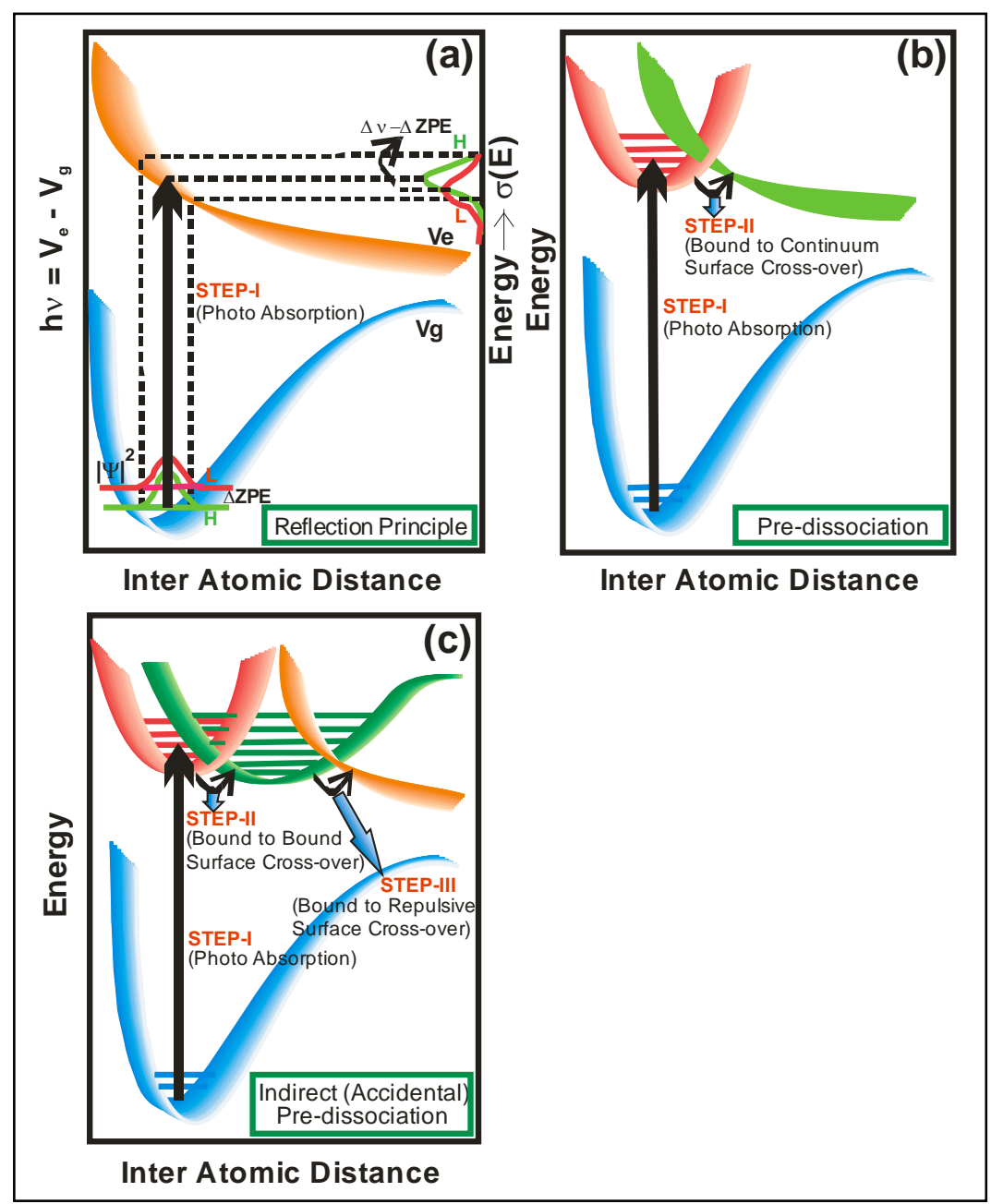

Figure 1. 


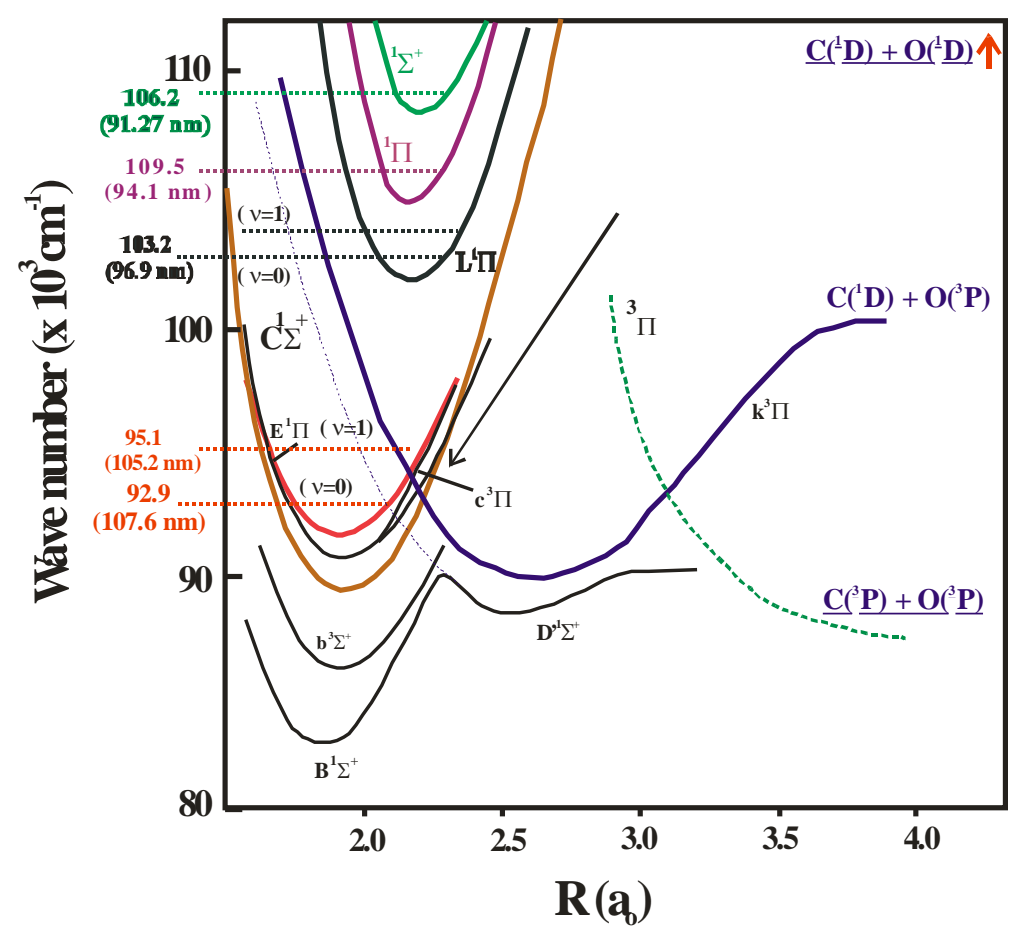

Figure 2.

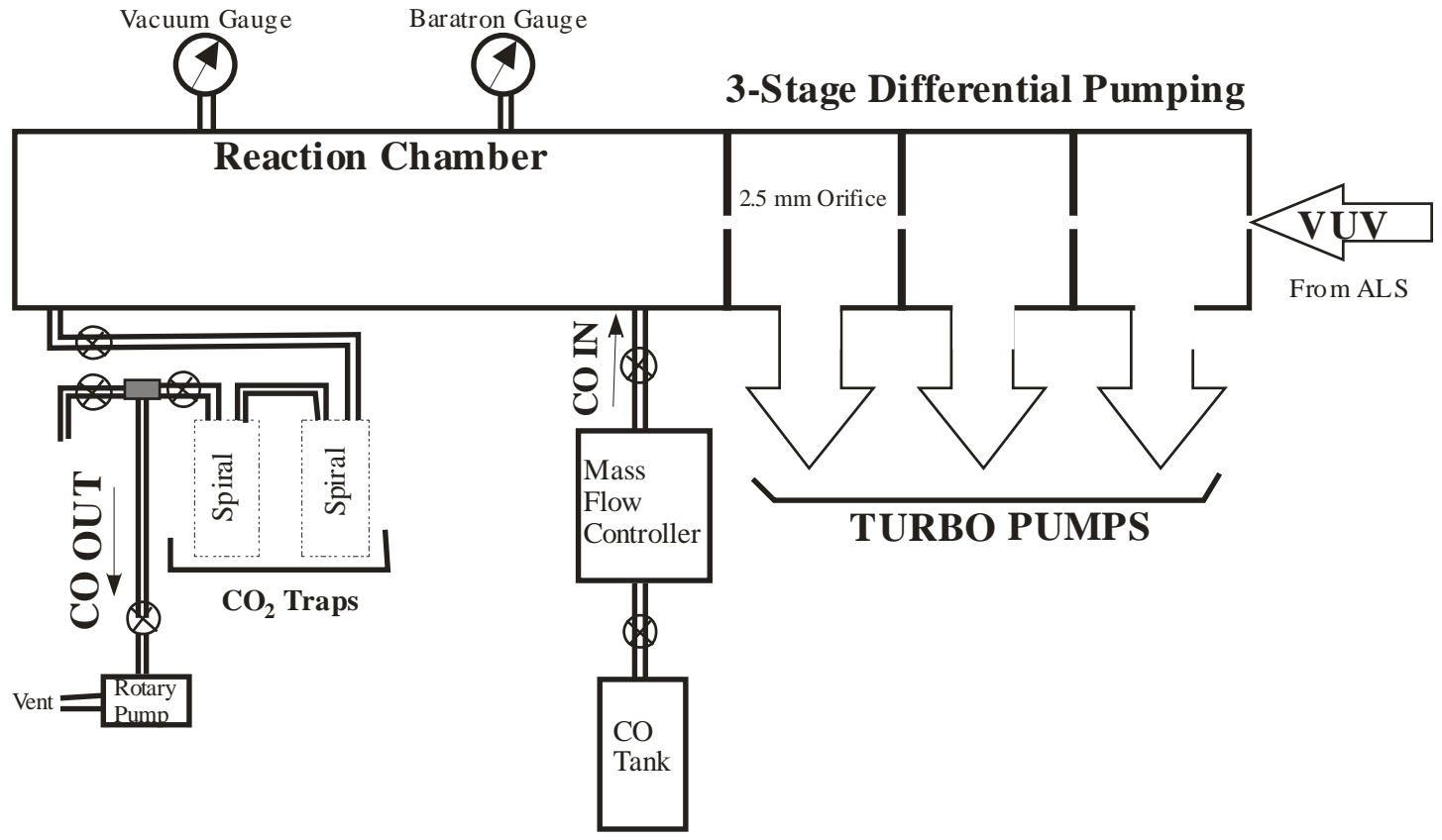

Figure 3. 


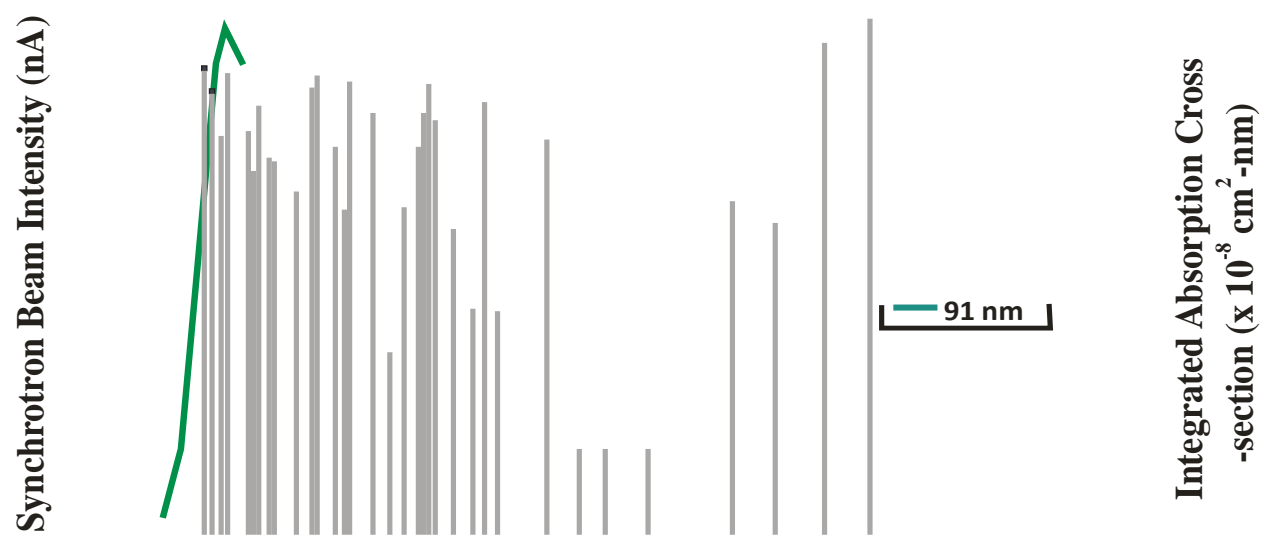

Wavelength (nm)

Figure 4.

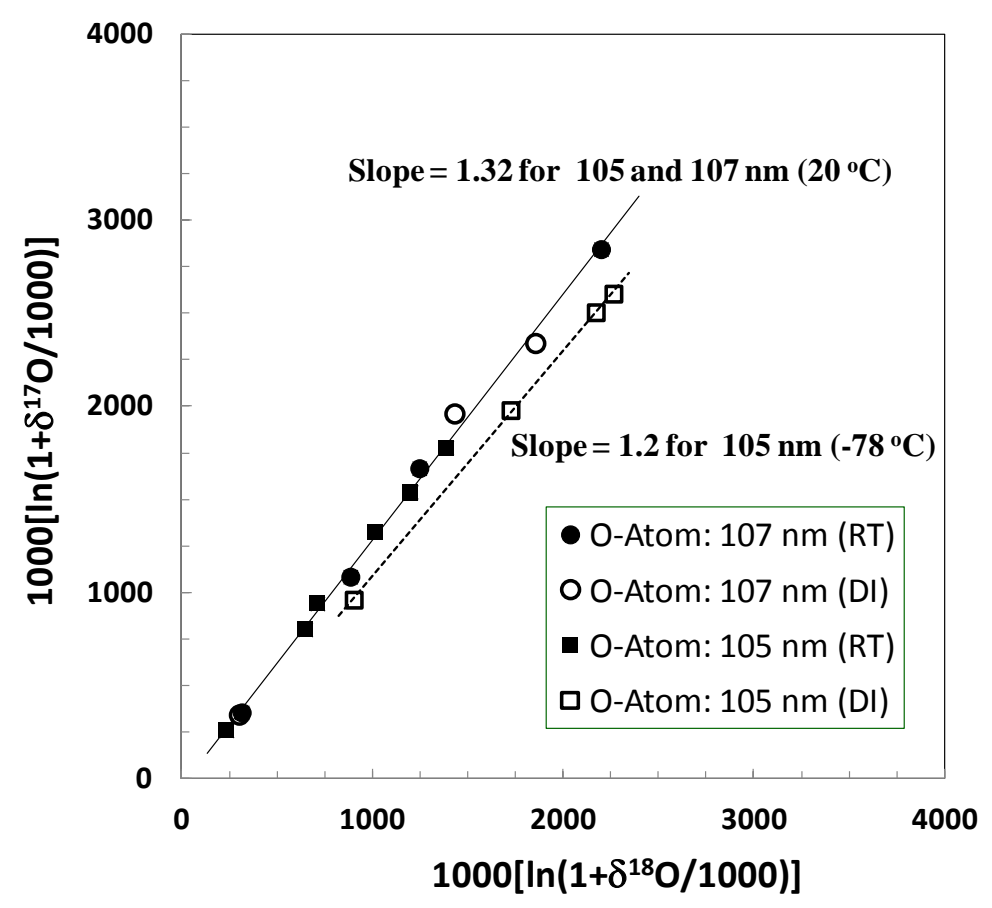

Figure 5(a). 


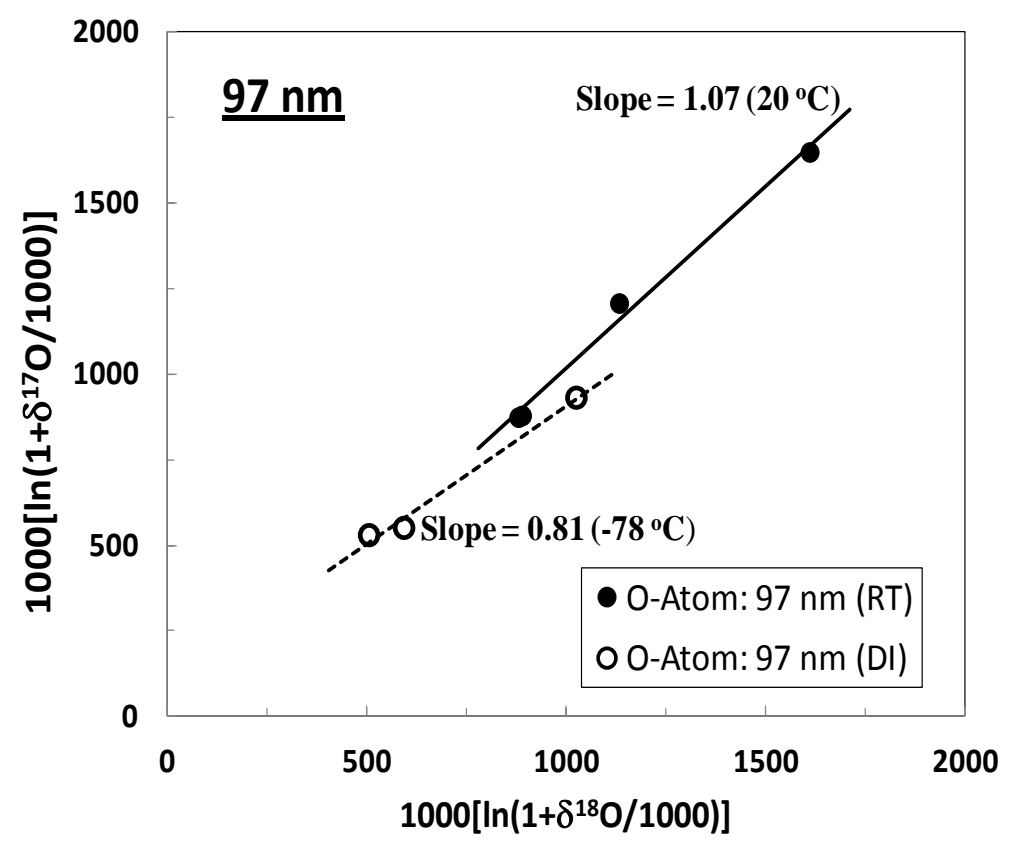

Figure 5(b).

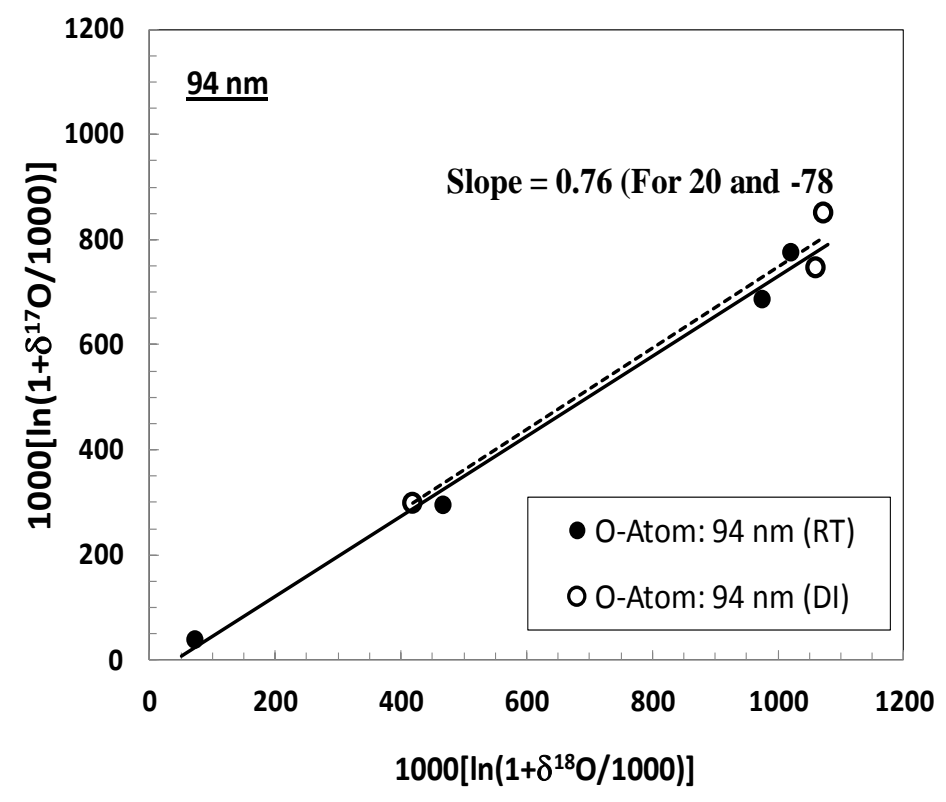

Figure 5(c). 


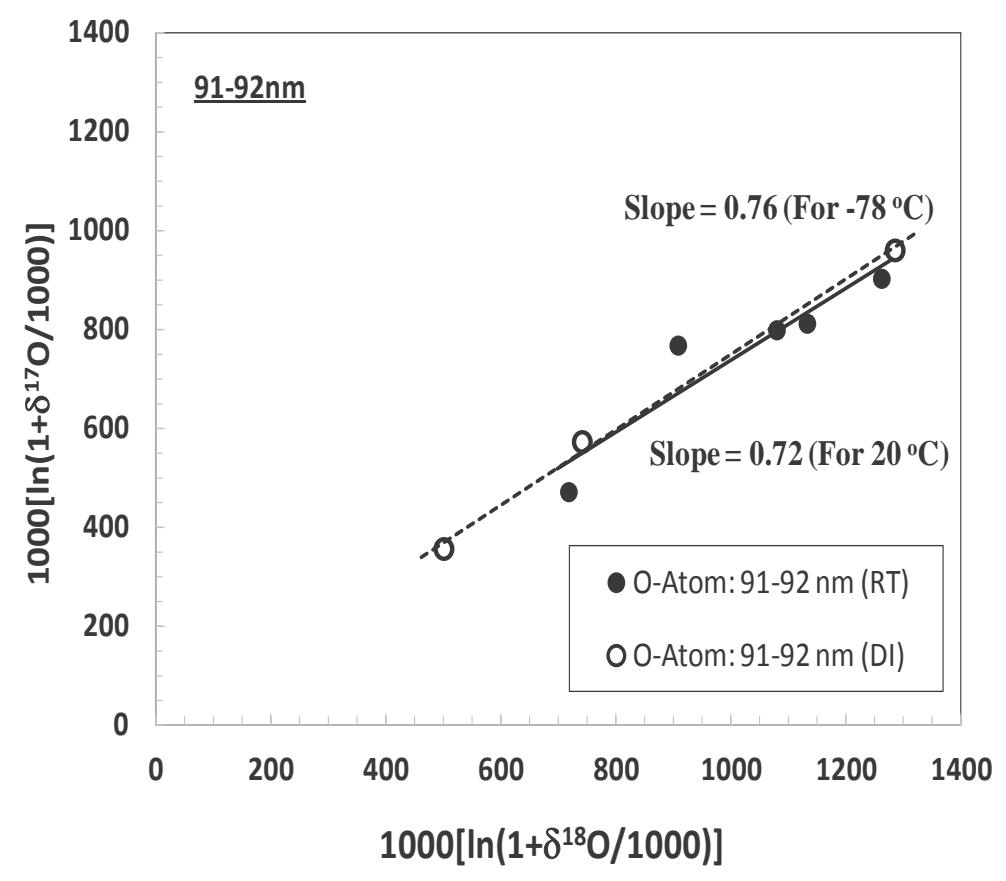

Figure 5(d).

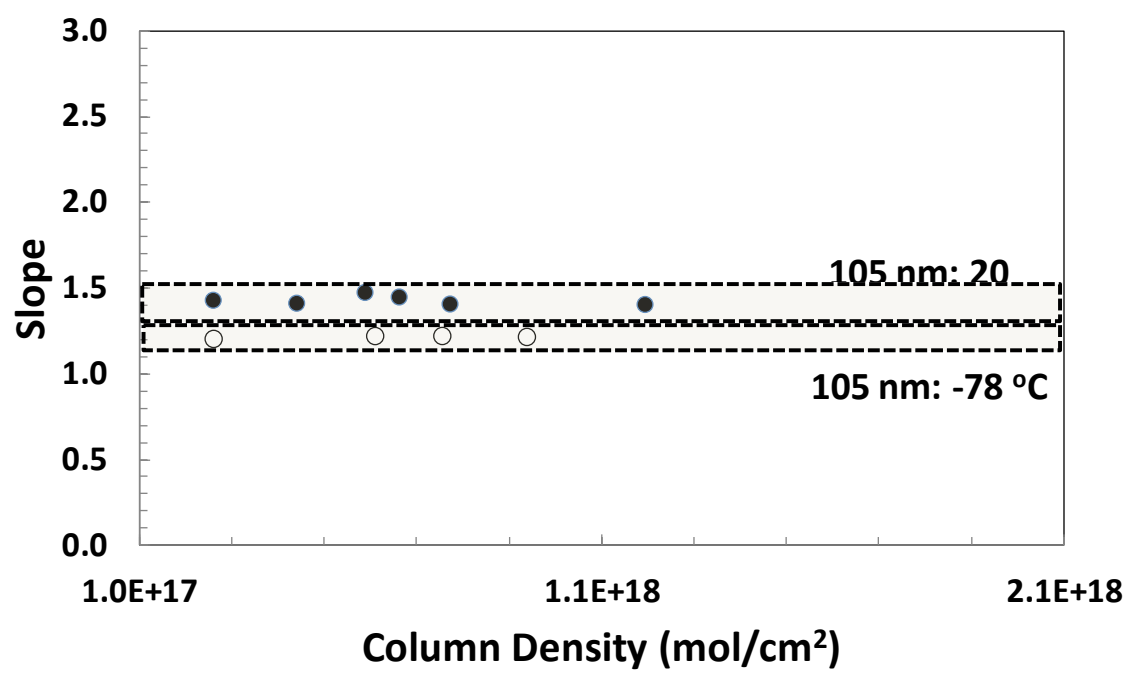

Figure 6. 
Table 1.

\begin{tabular}{|c|c|c|c|c|c|c|c|c|c|c|c|c|c|c|c|}
\hline \multirow{2}{*}{$\begin{array}{c}\text { Experiment } \\
\text { Number }^{1}\end{array}$} & \multirow{2}{*}{$\begin{array}{c}\text { VUV } \\
\text { Exposure } \\
\text { (min) }\end{array}$} & \multirow{2}{*}{$\begin{array}{l}\text { Pressure } \\
\text { (mTorr) }\end{array}$} & \multirow{2}{*}{ 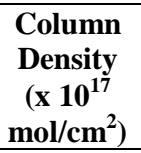 } & \multirow{2}{*}{$\begin{array}{c}\text { Chamber } \\
\text { Length } \\
(\mathrm{cm})\end{array}$} & \multirow{2}{*}{$\begin{array}{c}\text { CO } \\
\text { Residence } \\
\text { Time } \\
\text { (min) }\end{array}$} & \multicolumn{7}{|c|}{ Measured: Product $\mathrm{CO}_{2}$} & \multicolumn{3}{|c|}{ Atomic Oxygen Composition } \\
\hline & & & & & & $\begin{array}{c}\text { Amount } \\
(\mu \text { mole })\end{array}$ & $\delta^{17} \mathrm{O}$ & $\delta^{18} \mathrm{O}$ & $\delta^{\prime 17} \mathbf{O}^{2}$ & $\delta^{\prime 18} \mathrm{O}$ & $\begin{array}{c}\text { Instantaneous } \\
\text { Slope }\end{array}$ & $\Delta^{17} \mathbf{O}$ & $\delta^{17} \mathrm{O}$ & $\delta^{\prime 18} \mathrm{O}$ & $\begin{array}{c}\text { Instantaneous } \\
\text { Slope }\end{array}$ \\
\hline \multicolumn{16}{|c|}{$107.61 \mathrm{~nm}(11.52 \mathrm{eV}, 92928.2 \mathrm{~cm}-1)$ at Room Temperature $\left(20^{\circ} \mathrm{C}\right)$} \\
\hline ALS-10-11 & 465 & 39 & 1.3 & 105 & 189.3 & 0.9 & 173.2 & 141.1 & 182.8 & 148.3 & 1.23 & 106.4 & 355.5 & 314.6 & 1.13 \\
\hline ALS-09-14 & 650 & 45 & 2.7 & 182.5 & 251.6 & 0.41 & 800.5 & 523.1 & 676.1 & 522.1 & 1.30 & 407.3 & 1084.6 & 884.2 & 1.23 \\
\hline ALS-07-14 & 190 & 150 & 6.4 & 130 & 53.6 & 0.27 & 904.9 & 498.8 & 1143.2 & 767.9 & 1.49 & 747.8 & 1667.6 & 1245.9 & 1.34 \\
\hline ALS-07-15 & 510 & 250 & 11.0 & 130 & 32.2 & 0.45 & 5167.7 & 2430.0 & 2206.7 & 1567.1 & 1.41 & 1399.7 & 2844.8 & 2198.8 & 1.29 \\
\hline \multicolumn{16}{|c|}{$107.61 \mathrm{~nm}(11.52 \mathrm{eV}, 92928.2 \mathrm{~cm}-1)$ at DI Temperature $\left(-78^{\circ} \mathrm{C}\right)$} \\
\hline ALS-10-10 & 940 & 41 & 1.4 & 105 & 180.1 & 1.25 & 190.9 & 149.3 & 188.1 & 148.9 & 1.3 & 111.5 & 343.5 & 300.2 & 1.14 \\
\hline ALS09-03 & 915 & 123 & 7.4 & 182.5 & 92.0 & 0.31 & 3465.4 & 1813.6 & 1736.9 & 1299.7 & 1.34 & 1067.6 & 2340.4 & 1854.1 & 1.26 \\
\hline ALS-09-04 & 475 & 186 & 11.0 & 182.5 & 60.9 & 0.62 & 2554.4 & 1315.5 & 1397.1 & 941.9 & 1.48 & 912.1 & 1961.9 & 1430.2 & 1.37 \\
\hline \multicolumn{16}{|c|}{$105.17 \mathrm{~nm}(11.79 \mathrm{eV}, 95084.2 \mathrm{~cm}-1)$ at Room Temperature $\left(20^{\circ} \mathrm{C}\right)$} \\
\hline ALS-09-09 & 634 & 43 & 2.6 & 182.5 & 188.7 & 0.71 & 408.2 & 293.9 & 369.3 & 257.7 & 1.43 & 236.6 & 801.5 & 647.9 & 1.24 \\
\hline ALS-09-08 ${ }^{3}$ & 750 & 60 & 3.6 & 182.5 & 263.3 & 0.67 & 116.5 & 94.0 & 126.6 & 101.8 & 1.24 & 74.2 & 259.1 & 234.5 & 1.10 \\
\hline ALS-07-08 & 890 & 103 & 4.4 & 130 & 78.1 & 0.49 & 1147.1 & 686.2 & 1037.8 & 733.0 & 1.42 & 660.3 & 1541.6 & 1200.1 & 1.28 \\
\hline ALS-07-02 & 450 & 373 & 5.9 & 48 & 8.0 & 1.17 & 670.3 & 412.4 & 569.8 & 385.3 & 1.48 & 371.4 & 940.6 & 711.6 & 1.32 \\
\hline ALS-07-03 & 450 & 420 & 6.6 & 48 & 7.1 & 0.70 & 1177.9 & 700.2 & 862.0 & 593.6 & 1.45 & 556.3 & 1324.8 & 1012.4 & 1.31 \\
\hline ALS-07-06 & 600 & 490 & 7.7 & 48 & 6.1 & 1.14 & 1809.7 & 1079.3 & 1033.1 & 732.1 & 1.41 & 656.1 & 1535.8 & 1198.9 & 1.28 \\
\hline ALS-07-07 & 860 & 280 & 12.0 & 130 & 28.7 & 0.64 & 2445.9 & 1407.0 & 1237.2 & 878.4 & 1.41 & 784.8 & 1777.9 & 1387.5 & 1.28 \\
\hline \multicolumn{16}{|c|}{$105.17 \mathrm{~nm}(11.79 \mathrm{eV}, 95084.2 \mathrm{~cm}-1)$ at DI Temperature $\left(-78^{\circ} \mathrm{C}\right)$} \\
\hline ALS-10-14 & 510 & 75 & 2.6 & 105 & 98.4 & 0.95 & 794.6 & 707.3 & 646.0 & 534.9 & 1.20 & 370.5 & 961.2 & 902.0 & 1.07 \\
\hline ALS-07-04 & 450 & 387 & 6.1 & 48 & 7.7 & 0.65 & 2031.5 & 1424.0 & 1413.0 & 1154.0 & 1.22 & 818.6 & 1979.9 & 1724.4 & 1.15 \\
\hline ALS-07-09 & 825 & 177 & 7.5 & 130 & 45.4 & - & 43.5 & 43.5 & 1889.2 & 1542.5 & 1.22 & 1094.8 & 2505.8 & 2171.4 & 1.15 \\
\hline ALS-07-11 & 450 & 220 & 9.4 & 130 & 36.6 & 0.41 & 2908.4 & 1905.3 & 1982.0 & 1625.7 & 1.22 & 1144.8 & 2605.7 & 2264.1 & 1.15 \\
\hline \multicolumn{16}{|c|}{$97.03 \mathrm{~nm}(12.78 \mathrm{eV}, 103060.9 \mathrm{~cm}-1)$ at Room Temperature $\left(20^{\circ} \mathrm{C}\right)$} \\
\hline ALS-09-11 & 480 & 60 & 3.6 & 182.5 & 188.7 & 0.86 & 510.4 & 511.8 & 526.3 & 526.0 & 1.00 & 255.4 & 880.1 & 889.6 & 0.99 \\
\hline ALS-10-05 & 480 & 120 & 4.1 & 105 & 61.5 & 0.61 & 476.7 & 472.4 & 522.6 & 519.3 & 1.01 & 255.2 & 874.9 & 880.4 & 0.99 \\
\hline ALS-07-12 & 435 & 160 & 6.8 & 130 & 50.3 & 0.88 & 829.8 & 703.1 & 805.4 & 717.2 & 1.12 & 436.1 & 1208.4 & 1133.1 & 1.07 \\
\hline ALS-09-06 & 470 & 197 & 12 & 182.5 & 57.5 & 1.04 & 2476.4 & 1790.2 & 1255.0 & 1091.5 & 1.15 & 692.9 & 1650.0 & 1610.9 & 1.12 \\
\hline \multicolumn{16}{|c|}{$97.03 \mathrm{~nm}(12.78 \mathrm{eV}, 103060.9 \mathrm{~cm}-1)$ at DI Temperature $\left(-78{ }^{\circ} \mathrm{C}\right)$} \\
\hline ALS-10-06 & 740 & 10 & 3.5 & 105 & 72.4 & 0.67 & 331.2 & 325.0 & 328.7 & 321.5 & 1.0 & 163.1 & 529.6 & 506.5 & 1.05 \\
\hline ALS-10-04 & 470 & 120 & 4.1 & 105 & 61.5 & 0.92 & 716.2 & 818.0 & 563.1 & 626.2 & 0.9 & 240.6 & 931.3 & 1026.4 & 0.91 \\
\hline ALS-10-07 & 780 & 175 & 6.0 & 105 & 437.5 & 0.78 & 325.6 & 373.6 & 303.4 & 340.6 & 0.9 & 128.0 & 550.8 & 594.2 & 0.93 \\
\hline \multicolumn{16}{|c|}{$94.12 \mathrm{~nm}(13.18 \mathrm{eV}, 106247.3 \mathrm{~cm}-1)$ at Room Temperature $\left(20^{\circ} \mathrm{C}\right)$} \\
\hline ALS-09-13 & 720 & 44 & 2.6 & 182.5 & 283.0 & 1.31 & 487.0 & 739.3 & 393.4 & 587.1 & 0.67 & 91.0 & 688.1 & 973.7 & 0.71 \\
\hline ALS-09-10 & 450 & 55 & 3.3 & 182.5 & 205.8 & 1.00 & 523.3 & 667.0 & 454.2 & 620.9 & 0.73 & 134.4 & 777.2 & 1019.3 & 0.76 \\
\hline
\end{tabular}

${ }^{1}$ Experiment numbers indicated in the format ALS-07-XX are from previous publications (Ref), others (i.e., ALS-09-XX and ALS-10-XX) are new data.

${ }^{2} \delta^{\mathrm{x}} \mathrm{O}=1000 \mathrm{x} \ln \left(1+\delta^{\mathrm{x}} \mathrm{O} / 1000\right)$

${ }^{3}$ During fluorination, sample tube was found to be contaminated with relatively large amount of water vapor and separated from $\mathrm{CO}_{2}$ using $-70{ }^{\circ} \mathrm{C}$ slush

${ }^{4}$ Air-leakage in fluorination tube 


\begin{tabular}{|c|c|c|c|c|c|c|c|c|c|c|c|c|c|c|c|}
\hline ALS-07-01 & 290 & 250 & 3.9 & 48 & 11.9 & 1.54 & 159.7 & 258.8 & 148.1 & 230.2 & 0.64 & 29.6 & 296.5 & 465.9 & 0.64 \\
\hline ALS- $07-10^{5}$ & 430 & 165 & 7.0 & 130 & 18.0 & 0.56 & 7.7 & 11.7 & 7.6 & 11.3 & 0.67 & 1.8 & 40.1 & 71.2 & 0.56 \\
\hline \multicolumn{16}{|c|}{$94.12 \mathrm{~nm}(13.18 \mathrm{eV}, 106247.3 \mathrm{~cm}-1)$ at DI Temperature $\left(-78^{\circ} \mathrm{C}\right)$} \\
\hline ALS-10-08 & 940 & 80 & 2.8 & 105 & 50.3 & 1.66 & 149.7 & 218.4 & 149.8 & 210.6 & 0.71 & 41.3 & 299.3 & 418.0 & 0.72 \\
\hline ALS-10-12 & 480 & 95 & 3.3 & 105 & 50.3 & 1.54 & 608.3 & 864.4 & 506.2 & 660.2 & 0.77 & 166.2 & 851.7 & 1071.7 & 0.79 \\
\hline ALS-07-13 & 435 & 160 & 6.8 & 130 & 50.3 & 0.72 & 542.9 & 873.7 & 459.6 & 662.1 & 0.69 & 118.6 & 747.4 & 1059.4 & 0.71 \\
\hline \multicolumn{16}{|c|}{$92.6 \mathrm{~nm}(13.39 \mathrm{eV}, 108003.0 \mathrm{~cm}-1)$ at Room Temperature $\left(20^{\circ} \mathrm{C}\right)$} \\
\hline ALS-09-02 & 915 & 120 & 7.2 & 182.5 & 94.3 & 1.63 & 677.1 & 1166.1 & 542.7 & 806.9 & 0.67 & 127.1 & 903.0 & 1261.9 & 0.72 \\
\hline ALS-09-01 & 915 & 124 & 7.4 & 182.5 & 91.3 & 0.20 & 149.6 & 259.5 & 253.4 & 405.3 & 0.63 & 44.6 & 471.5 & 717.6 & 0.66 \\
\hline ALS-09-07 & 390 & 153 & 9.2 & 182.5 & 74.0 & 1.13 & 658.8 & 937.4 & 478.5 & 706.3 & 0.68 & 114.7 & 812.2 & 1132.4 & 0.72 \\
\hline \multicolumn{16}{|c|}{$91.37 \mathrm{~nm}(13.572 \mathrm{eV}, 109445.1 \mathrm{~cm}-1)$ at Room Temperature $\left(20^{\circ} \mathrm{C}\right)$} \\
\hline ALS-10-01 & 280 & 40 & 1.4 & 105 & 185.0 & 0.51 & 383.4 & 487.2 & 447.8 & 539.1 & 0.83 & 170.1 & 768.0 & 907.9 & 0.85 \\
\hline ALS-10-02 & 482 & 100 & 3.5 & 105 & 73.8 & 0.7 & 428.4 & 679.5 & 469.2 & 666.1 & 0.70 & 126.2 & 798.9 & 1079.5 & 0.74 \\
\hline \multicolumn{16}{|c|}{$91.37 \mathrm{~nm}(13.572 \mathrm{eV}, 109445.1 \mathrm{~cm}-1)$ at DI Temperature $\left(-78^{\circ} \mathrm{C}\right)$} \\
\hline ALS-10-13 & 480 & 35 & 1.2 & 105 & 210.9 & 1.31 & 372.8 & 525.1 & 343.2 & 422.0 & 0.81 & 125.9 & 571.7 & 741.9 & 0.8 \\
\hline ALS-10-09 & 945 & 49 & 1.7 & 105 & 150.7 & 1.58 & 199.3 & 298.7 & 192.7 & 275.8 & 0.70 & 50.6 & 355.2 & 501.2 & 0.71 \\
\hline ALS-10-03 & 480 & 100 & 3.5 & 105 & 73.8 & 0.63 & 557.0 & 893.3 & 583.2 & 826.0 & 0.71 & 157.9 & 959.1 & 1286.0 & 0.75 \\
\hline
\end{tabular}

\footnotetext{
${ }^{5}$ For unknown reasons, the d-values were quite low compared to a similar experiment (ALS-07-01), though slope value was the same.
} 
This document was prepared as an account of work sponsored by the United States Government. While this document is believed to contain correct information, neither the United States Government nor any agency thereof, nor the Regents of the University of California, nor any of their employees, makes any warranty, express or implied, or assumes any legal responsibility for the accuracy, completeness, or usefulness of any information, apparatus, product, or process disclosed, or represents that its use would not infringe privately owned rights. Reference herein to any specific commercial product, process, or service by its trade name, trademark, manufacturer, or otherwise, does not necessarily constitute or imply its endorsement, recommendation, or favoring by the United States Government or any agency thereof, or the Regents of the University of California. The views and opinions of authors expressed herein do not necessarily state or reflect those of the United States Government or any agency thereof or the Regents of the University of California. 